\title{
Improving calibration and validation of cosmic-ray neutron sensors in the light of spatial sensitivity
}

\author{
Martin Schrön ${ }^{1,2}$, Markus Köhli ${ }^{1,3,4}$, Lena Scheiffele ${ }^{5}$, Joost Iwema ${ }^{6}$, Heye R. Bogena ${ }^{7}$, Ling Lv $^{8}$, Edoardo Martini $^{1}$, \\ Gabriele Baroni $^{2,5}$, Rafael Rosolem ${ }^{6,9}$, Jannis Weimar ${ }^{3}$, Juliane Mai ${ }^{2,10}$, Matthias Cuntz ${ }^{2,11}$, Corinna Rebmann ${ }^{2}$, \\ Sascha E. Oswald ${ }^{5}$, Peter Dietrich ${ }^{1}$, Ulrich Schmidt ${ }^{3}$, and Steffen Zacharias ${ }^{1}$ \\ ${ }^{1}$ Dept. Monitoring and Exploration Technologies, Helmholtz Centre for Environmental Research - UFZ, \\ Leipzig, Germany \\ ${ }^{2}$ Dept. Computational Hydrosystems, Helmholtz Centre for Environmental Research - UFZ, Leipzig, Germany \\ ${ }^{3}$ Physikalisches Institut, Heidelberg University, Heidelberg, Germany \\ ${ }^{4}$ Physikalisches Institut, University of Bonn, Bonn, Germany \\ ${ }^{5}$ Institute of Earth and Environmental Science, University of Potsdam, Postdam, Germany \\ ${ }^{6}$ Faculty of Engineering, University of Bristol, Bristol, UK \\ ${ }^{7}$ Agrosphere Institute (IBG-3), Forschungszentrum Jülich GmbH, Jülich, Germany \\ ${ }^{8}$ Dept. of Plants, Soils and Climate, Utah State University, Logan, USA \\ ${ }^{9}$ Cabot Institute, University of Bristol, Bristol, England \\ ${ }^{10}$ Dept. of Civil and Environmental Engineering, University of Waterloo, Waterloo, Canada \\ ${ }^{11}$ INRA, Université de Lorraine, UMR1137, Ecology et Ecophysiologie Forestière, Champenoux, France
}

Correspondence to: Martin Schrön (martin.schroen@ufz.de)

Received: 14 March 2017 - Discussion started: 27 March 2017

Revised: 24 June 2017 - Accepted: 26 August 2017 - Published: 6 October 2017

\begin{abstract}
In the last few years the method of cosmic-ray neutron sensing (CRNS) has gained popularity among hydrologists, physicists, and land-surface modelers. The sensor provides continuous soil moisture data, averaged over several hectares and tens of decimeters in depth. However, the signal still may contain unidentified features of hydrological processes, and many calibration datasets are often required in order to find reliable relations between neutron intensity and water dynamics. Recent insights into environmental neutrons accurately described the spatial sensitivity of the sensor and thus allowed one to quantify the contribution of individual sample locations to the CRNS signal. Consequently, data points of calibration and validation datasets are suggested to be averaged using a more physically based weighting approach. In this work, a revised sensitivity function is used to calculate weighted averages of point data. The function is different from the simple exponential convention by the extraordinary sensitivity to the first few meters around the probe, and by dependencies on air pressure, air humidity, soil moisture, and vegetation. The approach is extensively
\end{abstract}

tested at six distinct monitoring sites: two sites with multiple calibration datasets and four sites with continuous time series datasets. In all cases, the revised averaging method improved the performance of the CRNS products. The revised approach further helped to reveal hidden hydrological processes which otherwise remained unexplained in the data or were lost in the process of overcalibration. The presented weighting approach increases the overall accuracy of CRNS products and will have an impact on all their applications in agriculture, hydrology, and modeling.

\section{Introduction}

Field-scale soil moisture is an important variable to drive and evaluate agricultural, hydrological, and land-surface models (Vereecken et al., 2008; Robinson et al., 2008). Knowledge about soil moisture states at relevant scales would have direct implications for flood risk assessment (Norbiato et al., 2008), 
real-time estimation of water deficit in agriculture (Smith et al., 2002), or drought forecasting and analysis (Sheffield, 2004; Samaniego et al., 2013; Ceppi et al., 2014; Zink et al., 2016). Consequently, the corresponding models raise a huge demand for accurate estimations of root-zone soil moisture at scales from 10 to $10^{4} \mathrm{~m}$.

Cosmic-ray neutron sensing (CRNS) is one of the most promising methods for root-zone soil moisture monitoring at the field scale. These instruments are able to continuously measure soil water content averaged over several hectares and up to half a meter in depth (Zreda et al., 2012; Köhli et al., 2015). They are one of the few candidates to close the scale gap between point data and remote-sensing products (Robinson et al., 2008; Bogena et al., 2015).

After the measurement method was first presented by Zreda et al. (2008), many studies were dedicated to calibrating the sensors and to assessing the performance in comparison to conventional instruments (e.g., Rivera Villarreyes et al., 2011; Franz et al., 2012a; Coopersmith et al., 2014; Hawdon et al., 2014; Almeida et al., 2014). These studies showed a good agreement between neutron intensity and independent soil moisture observations. However, outstanding features were also reported in the CRNS data which did not fit well to the accepted theory described by Desilets et al. (2010). Authors suggested that additional hydrological processes and hydrogen pools could influence the signal (e.g., Franz et al., 2013a; Baatz et al., 2014; Baroni and Oswald, 2015), while others applied recalibration of semiphysical parameters to better fit individual site conditions (e.g., Rivera Villarreyes et al., 2011; Lv et al., 2014; Iwema et al., 2015; Heidbüchel et al., 2016). Despite the unambiguous improvements obtained by corrections and recalibration approaches, some features in many datasets could still not be explained using current knowledge and consequently seemed to be unrelated to hydrological processes.

To address some of these knowledge gaps, Franz et al. (2012b) investigated soil hydrological processes with water transport simulations and found that wetting and drying cycles are non-uniquely represented by the CRNS signal. Due to the integrative neutron signal, those hysteresis effects can be most significant when sharp wetting or drying fronts shape the soil water profile. As a consequence, Franz et al. (2012b) and Franz et al. (2013b) recommended vertical weighting of point measurements in the profile to account for these effects. Furthermore, Franz et al. (2013b) also demonstrated that the sensor could underestimate average soil moisture by up to 10 volumetric percent depending on the horizontal distribution of water content in the footprint. They concluded that exact knowledge of the heterogeneity is a prerequisite for the interpretation of neutron count rates, and distance-weighting procedures are necessary to obtain sufficient performance during calibration and validation with point data. In order to average calibration and validation data horizontally, Franz et al. (2012a) adopted a sampling scheme based on initial calculations by Zreda et al. (2008) to give every sample an equal weight. The resulting sensor locations at 25,75 , and $200 \mathrm{~m}$ correspond to an almost exponential horizontal weighting function. Bogena et al. (2013) were the first who applied this horizontal weighting to an irregularly distributed point sensor network, albeit indirectly by fitting the cumulative variant. Nevertheless, many researchers still avoid horizontal weighting by virtually re-locating their irregularly distributed point sensors to the nearest radius of 25,75 , or $200 \mathrm{~m}$ in postprocessing mode (e.g., Franz et al., 2012a). In complex terrain, only a few calibration or validation locations are accessible and their individual contribution to the neutron signal has been unknown for a long time.

As the understanding of cosmic-ray neutron physics in the environment has been more and more elaborated, Köhli et al. (2015) developed a dedicated computer model, URANOS, which helped to understand the spatial sensitivity of the neutron sensor. These authors revealed that the sensor is extraordinarily sensitive to the nearest few meters, rather than following a simple exponential decrease in sensitivity as was reported by Zreda et al. (2008) and Desilets and Zreda (2013). This revision has since changed the way CRNS measurements are interpreted. Their findings extensively describe the footprint volume in which soil water content is measured, and can now be used to develop new weighting approaches and to revisit previous data analysis.

The revised footprint and spatial sensitivity of the CRNS probe have since been confirmed by many observations. Heidbüchel et al. (2016) were the first to test the impact of the revised function on the performance of their calibration data. Schattan et al. (2017) applied the revised weighting approach to average complex snow patterns in an alpine terrain. Encouraged by both of their promising results, the present study has hypothesized that this new theory could enable an improved performance of CRNS calibration and validation campaigns for a huge variety of sites and conditions. We further hypothesize that the initially published relation between neutrons and water equivalent (Desilets et al., 2010) might be widely applicable without the need to calibrate all of its parameters on site-specific conditions. Eventually, an overall improvement of the CRNS data could help to identify hydrological effects more accurately (such as precipitation, ponding, evapotranspiration, and infiltration processes).

The paper is structured as follows: firstly, we present the equally weighted, the conventional, and the revised formulations of the spatial sensitivity function (also called the weighting function). We then provide a procedure to generate a weighted average of point measurements that can be compared with the CRNS product. The assumptions and uncertainties of this approach are then discussed, followed by a short description of measures used to evaluate the calibration performance, and short descriptions of the studied sites. In the results section we present and discuss the sensor performance using the equal, conventional, and revised weighting approaches for calibration campaigns at two different sites, and for time series data at four sites. 


\section{Methods}

Stationary cosmic-ray neutron sensors (CRNSs) are particle detectors that measure the neutron intensity in the wellmixed pool of neutrons above the land surface (Zreda et al., 2012). Due to the low interaction probability of neutrons with air molecules, the measured particles can travel distances of more than $240 \mathrm{~m}$ from the soil to the detector (Köhli et al., 2015). The neutron signal is predominantly sensitive to the number of hydrogen atoms in the soil, but it is also influenced by changes in air pressure, air humidity, and incoming cosmic radiation. These additional factors can be accounted for by standard correction approaches (Hawdon et al., 2014; Schrön et al., 2015), such that the remaining signal represents only the hydrogen abundance in the soil and biosphere. To convert the corrected neutron count rate $N$ to gravimetric soil water equivalent, $\theta$, Desilets et al. (2010) suggested the following theoretical relation:

$\theta\left(N, N_{0}\right)=\frac{0.0808}{N / N_{0}-0.372}-0.115$,

where $N_{0}$ is a site-specific calibration parameter. It is determined once for each dataset by comparing the CRNS product, $\theta\left(N, N_{0}\right)$, with the actual soil moisture condition in the field. However, neutrons are sensitive to all kinds of hydrogen in the footprint; hence, the variable $\theta$ denotes the water equivalent of soil moisture, $\theta_{\mathrm{sm}}$, and additional hydrogen pools, $\theta_{\text {offset }}$. The latter comprises for example lattice water, $\theta_{\mathrm{lw}}$ (Dong et al., 2014), as well as the water equivalent from soil organic carbon, $\theta_{\text {org }}$ (Hawdon et al., 2014), biomass, $\theta_{\text {bio }}$, and other dynamic contributors, $\theta_{\text {other: }}$ :

$\theta=\theta_{\text {sm }}+\theta_{\text {offset }}$, where $\theta_{\text {offset }}=\theta_{\text {lw }}+\theta_{\text {org }}+\theta_{\text {bio }}+\theta_{\text {other }}$.

Quantities related to absolute water equivalent are either given in units of gravimetric percent $\left(\theta_{\mathrm{g}}\right.$ in $\left.\% \equiv 100 \mathrm{~g} \mathrm{~g}^{-1}\right)$ or volumetric percent $\left(\theta_{\mathrm{v}}\right.$ in $\left.\% \equiv 100 \mathrm{~cm}^{3} \mathrm{~cm}^{-3}\right)$. If no indices " $\mathrm{v}$ " or " $\mathrm{g}$ " are indicated and units are not mentioned in the context, this work uses default units of volumetric percent.

For calibration and validation purposes, the water equivalent in the footprint volume is typically determined independently by an average of point measurements, for example from gravimetric samples or data from soil moisture monitoring networks. However, those locations can contribute differently to the apparent average of soil moisture as seen by the neutron detector, for example, depending on their distance $r$ from the CRNS probe and their depth $d$ below the soil surface. Depending on their individual contributions, different weights can be assigned to each data point in the calculation of a so-called weighted average.

Among the variety of weighting concepts in the literature, we have selected two of the main and most frequently used strategies from recognized publications, which are based on distinct physical assumptions. On the one hand, the conventional approach covers the main strategies applied so far
(Franz et al., 2012b; Bogena et al., 2013). On the other hand, a revised weighting approach has been used which is based on recent findings from Köhli et al. (2015) and which has been further advanced in the present work by the following points:

- extension of the analytical fit of the radial sensitivity function $W_{r}$ to short distances, $r \leq 0.5 \mathrm{~m}$, and

- added dependency of the weighting functions on air pressure $p$ and vegetation height $H_{\mathrm{veg}}$, by introducing a rescaled distance $r^{*}\left(r, p, H_{\mathrm{veg}}, \theta\right)$.

The URANOS neutron transport model has been updated accordingly to provide advanced analytical functions for the spatial sensitivity (URANOS 0.97 , available from http://www.ufz.de/uranos). These advancements generalize the applicability of the results from Köhli et al. (2015) and are recommended for future applications. Please refer to Appendix A for detailed explanations. There are certainly more factors that influence the shape of the neutron sensitivity, for example the height of the detector above ground, different plant species, and large objects. However, those factors are irrelevant for the investigated sites and are thus of minor importance for the conclusions in this work.

In addition to the conventional and revised approaches, this work includes the equal average weighting strategy (weights equal 1) to compare the performance when the CRNS signal is intuitively treated as a large-area averaging soil moisture product.

\subsection{Vertical weighting in the soil profile}

Simulations by Zreda et al. (2008), Franz et al. (2012b), and Köhli et al. (2015) have shown that the neutron signal integrated over a vertical soil column exhibits the highest sensitivity to the uppermost layers. Therefore, independent soil moisture measurements taken at different depths, $d$, need to be weighted differently in order to account for the underlying physical processes. To show the consequences of neglecting this step in post-processing, we have compared the equal average of soil samples with alternative weighting approaches.

The conventional vertical weighting, $W_{d}^{\text {conv }}$, is performed using a linear relation from Franz et al. (2012b), which was based on Monte Carlo simulations from Zreda et al. (2008) and became widely accepted in most previous studies.

$W_{d}^{\text {conv }}= \begin{cases}1-d / D^{\text {conv }}, & d \leq D^{\text {conv }} \\ 0, & d>D^{\text {conv }}\end{cases}$

penetration depth : $D^{\text {conv }} \equiv z^{*}(\theta)=\frac{5.8}{\theta+0.0829}$, in cm;

see Franz et al. (2012b).

The two major shortcomings of this function are (1) that it assumes similar penetration depths of detected neutrons for all distances $r$ from the sensor (see Fig. 1a), and (2) that it 
neglects any contribution of soil water below a certain cutoff penetration depth $D^{\text {conv }}$ (see Fig. 1b).

In contrast, the revised vertical weighting function, $W_{d}$, takes the full soil profile into account (as neutrons do) and considers the fact that the effective depth decreases with increasing distance $r$ from the detector:

$W_{d}\left(r, \theta, p, H_{\mathrm{veg}}\right)=e^{-2 d / D}$,

penetration depth : $D \equiv D_{86}\left(r^{*}, \theta, \varrho_{\text {bulk }}\right)$, in cm;

$$
\text { see Appendix A, }
$$

where $D$ denotes the effective penetration depth, defined as the depth within which $86 \%$ of neutrons probed the soil (see Köhli et al., 2015). These relations are based on URANOS simulations and follow recent insights about the physics of neutron transport and detection near the soil-atmosphere interface. Based on the formulation from Köhli et al. (2015) the advancements of the revised penetration depth $D \equiv D_{86}$ now add the dependency on air pressure and vegetation height, expressed in the scaled distance term $r^{*}$ (see Appendix A).

\subsection{Horizontal weighting in the footprint area}

In this work we make use of three horizontal weighting functions to average soil moisture measurements at distances $r$ from the CRNS probe. Firstly, the equal average (weights equal 1), which was usually applied for validation with soil moisture networks and remote sensing products. It was also used for calibration datasets if locations were arranged according to the COSMOS standard sampling scheme $(25,75$, $200 \mathrm{~m}$ ), such that the samples automatically represent areas of equal contribution to the neutron signal. These calculations were based on a simple exponential sensitivity function (Zreda et al., 2008) and presented by Franz et al. (2012a) and Zreda et al. (2012).

Secondly, the conventional weighting approach uses an (almost) exponential sensitivity function based on Monte Carlo simulations from Zreda et al. (2008). It is implicitly referred to when using the COSMOS standard sampling scheme (Zreda et al., 2012). An analytical form of the conventional horizontal weighting function has never been published. However, it can be derived from the cumulative function CFoC $(r)$, presented by Bogena et al. (2013, Eq. 13), who fitted data from Zreda et al. (2008, Fig. 3) in the domain of $r \leq 300 \mathrm{~m}$ :

$$
\begin{aligned}
e^{-r / 127} & \approx W_{r \leq 300}^{\text {conv }}=\partial_{r} \operatorname{CFoC}(r) \\
& \propto 1-a_{1} r+a_{2} r^{2}-a_{3} r^{3}+a_{4} r^{4},
\end{aligned}
$$

where

$a_{i}=\left\{1.311 \times 10^{-2}, 9.423 \times 10^{-5}, 3.2 \times 10^{-7}, 3.95 \times 10^{-10}\right\}$.

To account for the remaining contribution beyond $300 \mathrm{~m}$, the (usually few) data points have been assigned the weight
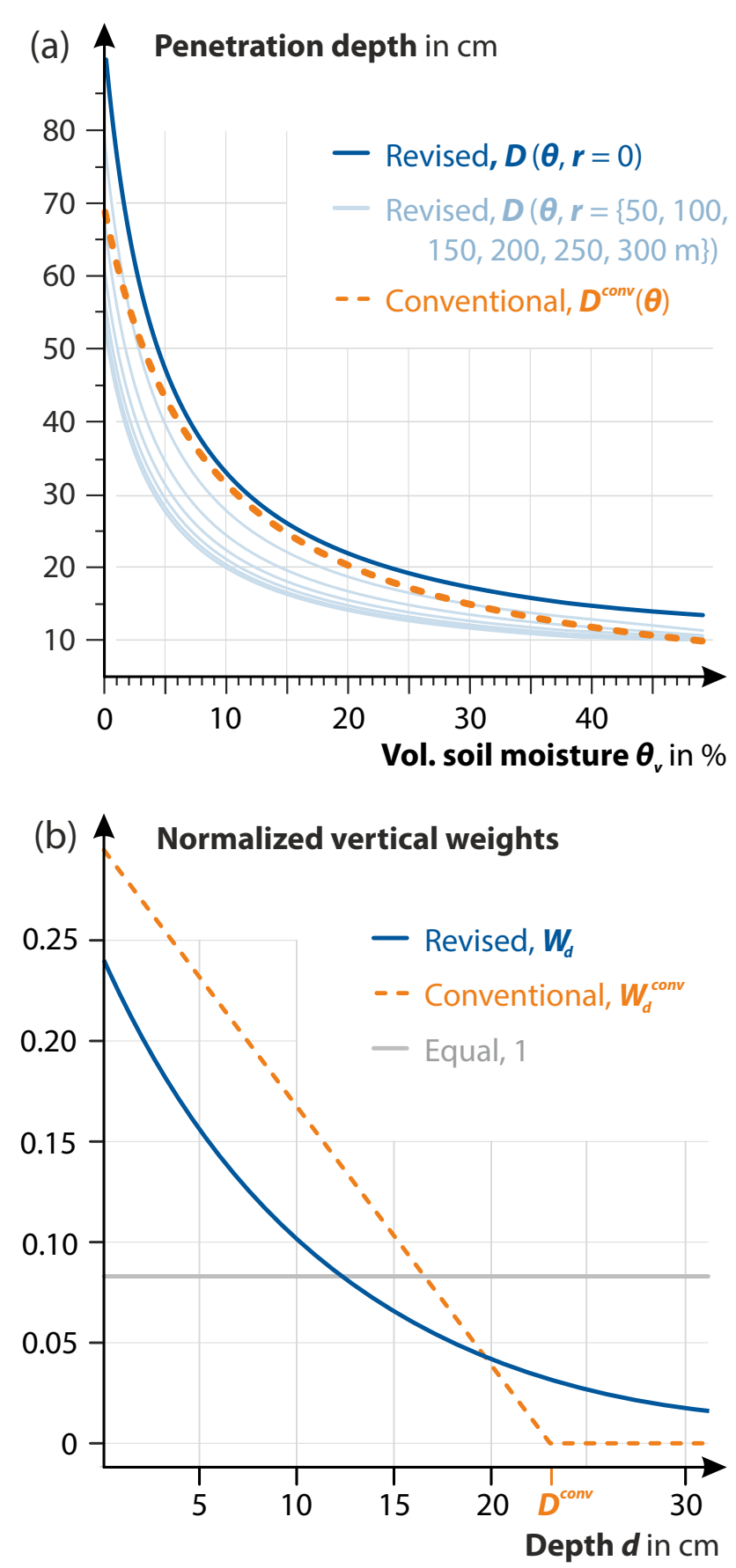

Figure 1. (a) A comparison between the revised and the conventional penetration depths, $D\left(\theta, r, \varrho_{\text {bulk }}=1.4 \mathrm{~g} \mathrm{~m}^{-3}\right)$ and $D^{\text {conv }}(\theta)$, respectively. On average, both approaches follow an almost similar shape; however, the conventional formulation is independent of distance $r$ and soil bulk density $\varrho_{\text {bulk }}$. (b) Normalized vertical weighting functions (Eqs. 3 and 4) based on 12 sample points. The conventional, linear approach overestimates the relative contribution from shallow water when compared to the revised, exponential function, and neglects contributions from depths beyond $D^{\text {conv }} \equiv z^{*}$ (=23 cm in this example). 


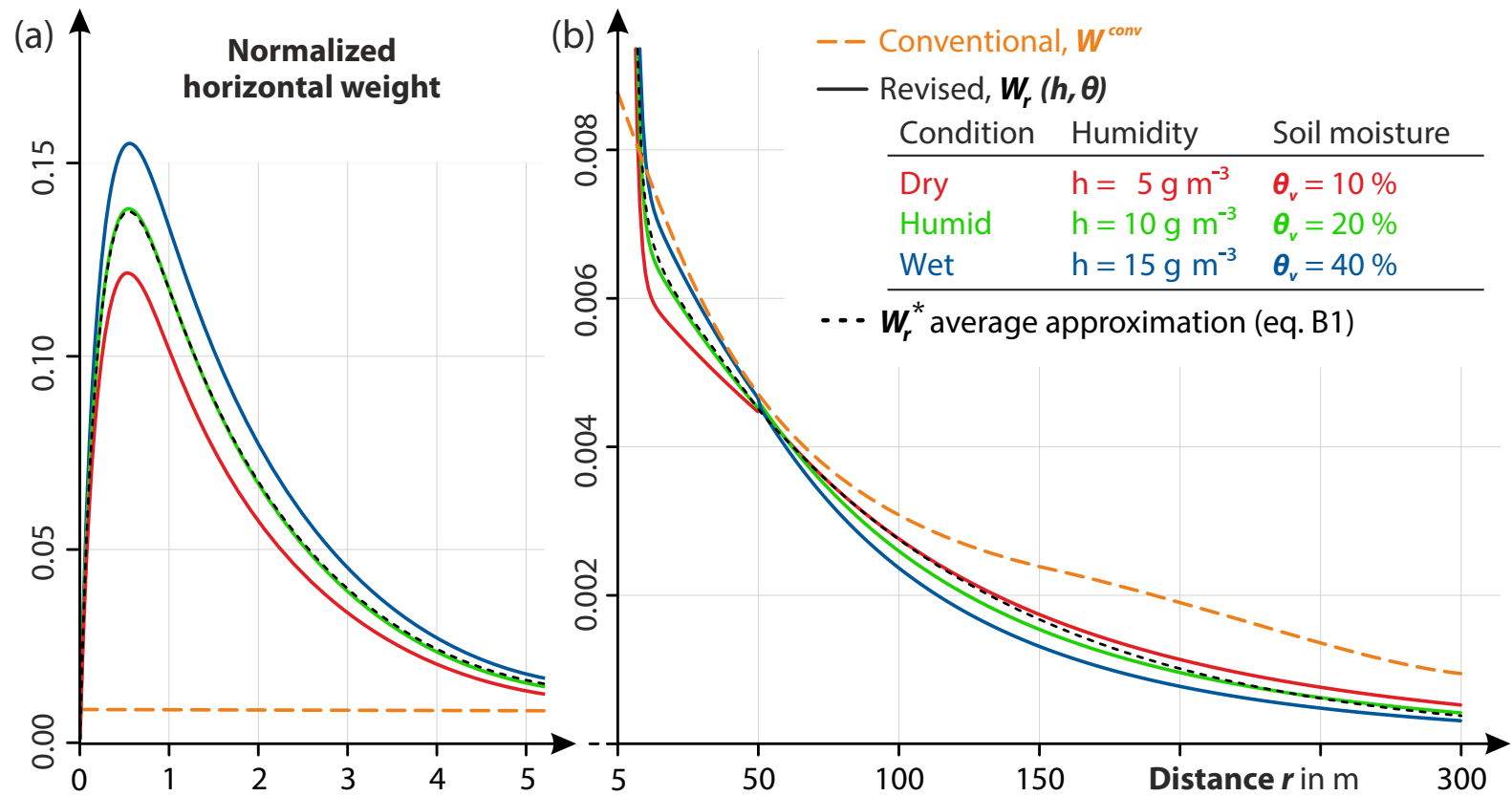

Figure 2. Comparison of normalized horizontal weighting functions (a) from 0 to $5 \mathrm{~m}$, and (b) from 5 to $300 \mathrm{~m}$. Graphs show the conventional (almost exponential) approach $W_{r}^{\text {conv }}\left(\right.$ Eq. 5), the revised curves $W_{r}(h, \theta)$ for three wetness conditions (Eq. 6), and an approximation $W_{r}^{*}$ based on a simplified equation (Appendix B). The conventional approach is insensitive to air and soil water content and highly underestimates the contribution of nearby areas $r<10 \mathrm{~m}$ when compared to the revised function.

$W_{r>300}^{\text {conv }}=W_{r=300}^{\text {conv }}$. One of the major shortcomings of this exponential approach is the underestimation of the high sensitivity of the neutron signal to the first few meters around the sensor.

As a third strategy, we use the revised weighting approach based on URANOS simulations and corresponding analytical fits (see Köhli et al., 2015, for details). New technical advancements of this function include the dependency on air pressure $p$ and humidity $h$ by introducing the rescaled distance $r^{*}$, as well as the extension below $r \leq 0.5 \mathrm{~m}$.

$$
\begin{aligned}
& W_{r}\left(h, \theta, p, H_{\mathrm{veg}}\right)= \\
& \begin{cases}\left(F_{1} e^{-F_{2} r^{*}}+F_{3} e^{-F_{4} r^{*}}\right)\left(1-e^{-F_{0} r^{*}}\right), & 0 \mathrm{~m}<r \leq 1 \mathrm{~m} \\
F_{1} e^{-F_{2} r^{*}}+F_{3} e^{-F_{4} r^{*}}, & 1 \mathrm{~m}<r \leq 50 \mathrm{~m} \\
F_{5} e^{-F_{6} r^{*}}+F_{7} e^{-F_{8} r^{*}}, & 50 \mathrm{~m}<r<600 \mathrm{~m}\end{cases}
\end{aligned}
$$

Parameter functions $F_{i}$, their corresponding parameters, the formulation of the rescaled distance $r^{*}\left(r, p, H_{\mathrm{veg}}, \theta\right)$, as well as further explanations are given in Appendix A.

\subsection{The weighting procedure}

The following procedure is recommended to generate a weighted average of point measurements that can be compared with the CRNS product (see the illustration in Fig. 3). For each experimental site, consider a number of soil profiles $P$ at distances $r_{P}$ from the CRNS probe. In each profile, point measurements of volumetric water equivalent $\theta_{P, L}$ are given at various layers $L$ of depth $d_{L}$. Observations of air pressure $p$, air humidity $h$, and vegetation height $H_{\mathrm{veg}}$ are given at the time of interest, while estimations of soil bulk density $\varrho_{\text {bulk }}$ exist for every profile (or even every sample). The general function to calculate an average of point measurements $i$ with values $\theta_{i}$ and weights $w_{i}$ is given as

$\mathrm{wt}(\theta, w)=\frac{\sum_{i} w_{i} \theta_{i}}{\sum_{i} w_{i}}$.

The procedure to obtain a weighted average of soil water equivalent, $\langle\theta\rangle$, is described as follows (see also Fig. 3).

1. Estimate an initial value $\langle\theta\rangle=\operatorname{wt}\left(\theta_{P, L}, 1\right)$ by an equally weighted average over all profiles $P$ and layers $L$.

2. Calculate the penetration depth $D_{P}$ for each profile $P$ :

$$
D_{P}^{\text {conv }}=z^{*}(\langle\theta\rangle)
$$

or

$$
D_{P}=D_{86}\left(\langle\theta\rangle, r_{P}^{*}\right) .
$$

3 . Vertically average the values $\theta_{P, L}$ over layers $L$, to obtain a weighted average for each profile $P$ :

$$
\theta_{P}^{\text {conv }}=\mathrm{wt}\left(\theta_{P, L}, W_{d_{L}}^{\text {conv }}\right),
$$

or

$$
\theta_{P}=\mathrm{wt}\left(\theta_{P, L}, W_{d_{L}}\right) \text {. }
$$




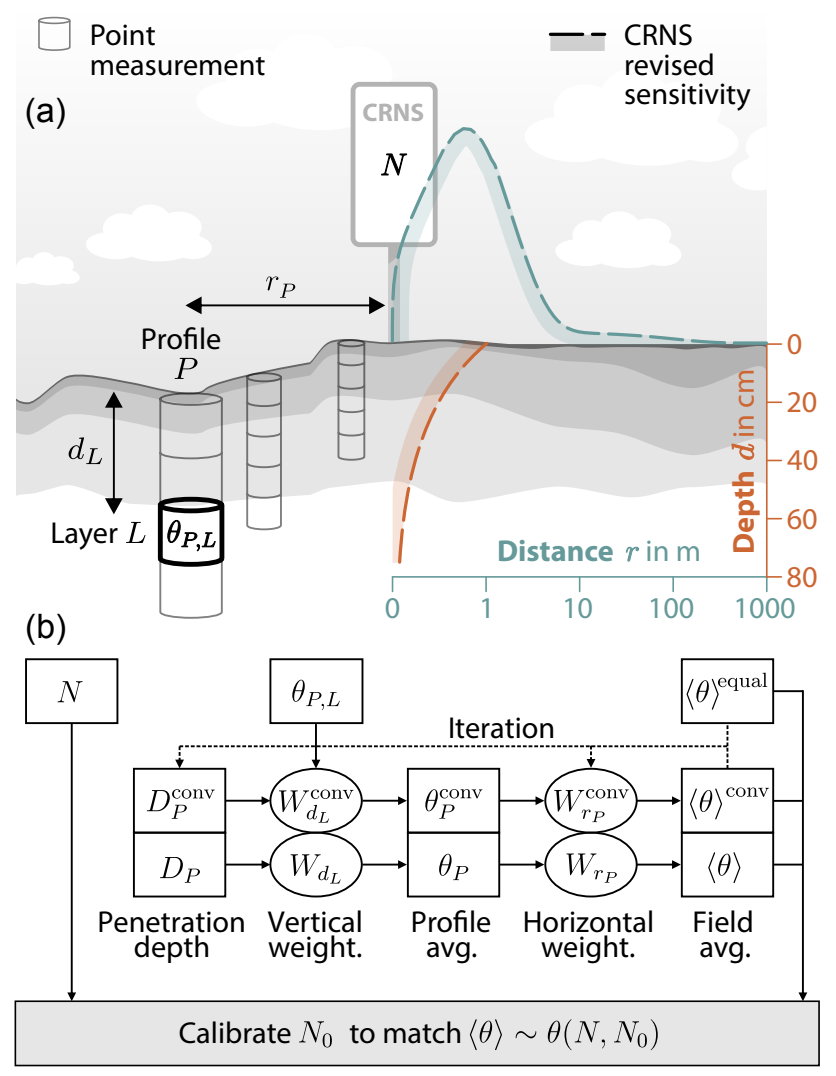

Figure 3. (a) Schematic of the environment around the cosmic-ray neutron sensor (CRNS) including point measurements (e.g., soil samples) of water equivalent $\theta$ to calibrate or validate the sensor. The revised sensitivity functions $W_{r}$ (teal) and $W_{d}$ (brown) are indicated (arb. scale). (b) The measured variables are used in the weighting procedure (Sect. 2.3), starting with an initial estimate of field-average water content. Three approaches, using the equal, the conventional (conv), and the revised weighting function are compared in this study. The resulting weighted-average water equivalent $\langle\theta\rangle$ is then used to calibrate against or validate with the CRNS product (Eq. 1). Calibration of the parameter $N_{0}$ is performed towards optimization of four performance measures (see Sect. 2.5).

4. Horizontally average the profiles $\theta_{P}$ :

$$
\langle\theta\rangle^{\text {conv }}=\operatorname{wt}\left(\theta_{P}^{\text {conv }}, W_{r_{P}}^{\text {conv }}\right),
$$

or

$$
\langle\theta\rangle=\operatorname{wt}\left(\theta_{P}, W_{r_{P}}\left(h,\langle\theta\rangle, p, H_{\mathrm{veg}}\right)\right) .
$$

5. Use the new $\langle\theta\rangle$ to reiterate through steps $1-5$ until values converge within a user-defined accuracy range (e.g., $1 \%)$.

The final averaged water equivalent $\langle\theta\rangle$ is then compared with the CRNS product, $\theta(N)$, derived from the neutron count rate $N$ (Eq. 1). It is also possible to calculate gravimetric water content using local bulk densities before step 3; however, this approach is not recommended since the revised weighting functions have been determined by simulations of homogeneous soil and volumetric water content (Köhli et al., 2015). While it has been assumed that $N_{0}$ accounts for persistent, non-homogeneous features in the footprint (Zreda et al., 2012), the influence of this state-of-the-art model assumption is to be investigated in future studies.

The above procedure weights each data point $\theta_{P, L}$ according to its depth $d$ and distance $r$ from the CRNS probe. However, when a finite number of sample points are chosen, assumptions are involved in the spatial domain they represent. Depending on knowledge about the individual field conditions, interpolation between soil layers, for instance, is a good option to assign each measurement to a certain soil horizon. Let $\Omega(r, \vartheta)$ (in $\mathrm{m}^{3}$ ) be the spatial domain of the footprint volume in polar coordinates (radius $r$, solid angle $\vartheta$ ), $\Omega_{P}$ (in $\mathrm{m}^{2}$ ) the horizontal representative area of the profile $P$, and $\Omega_{L}$ (in $\mathrm{m}$ ) the representative soil horizon of the measurement at layer $L$. As each measurement $\theta_{P, L}$ represents the volume $\Omega_{P} \cdot \Omega_{L}$, its weighted contribution to the neutron signal should be integrated over this domain.

Horizontal contribution of profile $P$ :

$w_{P}=\int_{\Omega_{P}} W_{r_{P}}=\int_{\Omega_{P}(r)} \frac{1}{2 \pi} \int_{\Omega_{P}(\vartheta)} W_{r} \cdot \mathrm{d} \vartheta \mathrm{d} r$.

Vertical contribution of layer $L$ :

$w_{L}=\int_{\Omega_{L}} W_{d_{L}}=\int_{\Omega_{L}(d)} W_{d} \cdot \mathrm{d} d$.

For example, if soil samples were taken at two depths, 10 and $40 \mathrm{~cm}$ for instance, it could be reasonable to integrate their weights from $d=0$ to $30 \mathrm{~cm}$ and from 30 to $50 \mathrm{~cm}$, respectively. In the horizontal space it might be sometimes reasonable to integrate a single profile measurement over the whole area of similar soil and land-use type (as has been done in Sect. 4.4). If sample locations were arranged in an interpolated, regular grid (e.g., pixels of size $1 \mathrm{~m}$ in Fig. 10), then each pixel should be weighted individually as a point such that the integrals above can be simplified. While an infinitesimal point at distance $r$ has the weight $W_{r} /(2 \pi r)$, a regular pixel of size $s$ at that distance weighs $W_{r} /(2 \pi r) \cdot s \propto W_{r} / r$. For all radially symmetric sampling schemes, where each point measurement represents one of $n$ circular sectors, the sector at distance $r$ has the size (arc length) of $2 \pi r / n$, and thus contributes the weight $W_{r} /(2 \pi r) \cdot(2 \pi r) / n \propto W_{r}$.

The strategy, to take into account estimations of representative volumes, initially appears to be more realistic. However, the extrapolation of data points involves assumptions about the site-specific heterogeneity and therefore about the strategy of interpolation. It further requires expert knowledge about the individual field conditions. During the preparation of this work, we found that the usage of weights for distinct measurement points provided fair approximations of the integrals, i.e., $W_{r_{P}} \approx w_{P}$ and $W_{d_{L}} \approx w_{L}$, and eventually resulted 
in almost similar averages, $\langle\theta\rangle$, throughout all cases investigated (not shown).

\subsection{Uncertainty due to partial coverage}

In addition to the considerations about the representative domain, the arrangement of the soil samples can play a crucial role for the CRNS evaluation performance. If the locations of the soil samples (or in situ monitored soil profiles) do not cover the CRNS footprint representatively, the corresponding data would not be able to explain parts of the neutron signal. Many sites exhibit highly irregular configurations where the soil monitoring network covers only parts of the CRNS footprint. The corresponding uncertainty in the CRNS evaluation can be estimated as follows.

Let $S$ be the domain of the representative volume of the sample locations (e.g., the areal extent of the soil moisture monitoring network), and let $\Omega$ be the spatial domain of the CRNS footprint as defined in the previous section. Then, the outer region $\Omega \backslash S$ denotes the part of the footprint domain which is not represented by the samples. The contribution of the "sample area" $S$ to the neutron signal then is

contribution : $N_{S} / N_{\Omega}=\int_{S} W_{r} / \int_{\Omega} W_{r}$,

which can range from 0 to $100 \%$ and depicts the fraction of detected neutrons which carry information from (i.e., had contact with) the sample area $S$. Assume that the observed soil moisture in $S$ is on average $\langle\theta\rangle$, and that the soil moisture in the outer region, $\Omega \backslash S$, can be estimated as $\langle\theta\rangle \pm \Delta \theta$. The propagation of this error through $W_{r}(h, \theta)$ leads to an uncertainty $\Delta N$ of the total neutron signal $N$,

$N \pm \Delta N=\int_{\Omega} W_{r} \approx \int_{S} W_{r}(h,\langle\theta\rangle)+\int_{\Omega \backslash S} W_{r}(h,\langle\theta\rangle \pm \Delta \theta)$,

and eventually adds uncertainty to the CRNS product, $\theta(N \pm \Delta N)$. In this paper, this estimation is applied exemplarily to the Schäfertal site (Sect. 4.2) in order to quantify the errors introduced by incomplete coverage.

\subsection{Performance measures}

To evaluate the performance of time series and calibration data, we apply prominent measures used in environmental and hydrological research. The robustness of this approach is evaluated by applying different performance measures, which is a common strategy to falsify new methodological approaches (see, e.g., Glaser et al., 2016). Popular efficiency measures are the Nash-Sutcliffe efficiency (NSE) (Nash and Sutcliffe, 1970) and the more modern KlingGupta efficiency (KGE) (Gupta et al., 2009), while the root mean square error (RMSE) and the Pearson correlation coefficient $(\rho)$ are well-established standard approaches.
$\mathrm{NSE}=1-\frac{\sum(A-B)^{2}}{\sum(B-\langle B\rangle)^{2}}$,

$\mathrm{KGE}=1-\left[(\rho(A, B)-1)^{2}+\left(\frac{\sigma_{A}}{\sigma_{B}}-1\right)^{2}+\left(\frac{\langle A\rangle}{\langle B\rangle}-1\right)^{2}\right]^{\frac{1}{2}}$,

$\operatorname{RMSE}=\left\langle(A-B)^{2}\right\rangle^{\frac{1}{2}}$,

$\rho=\frac{\langle(A-\langle A\rangle)(B-\langle B\rangle)\rangle}{\sigma_{A} \sigma_{B}}$,

where $A=\theta\left(N, N_{0}\right)$ denotes the water equivalent measured by the CRNS ( $N_{0}$ needs to be calibrated), $B$ denotes the actual field soil water equivalent, $\theta$, measured by independent instruments, and $\langle x\rangle=\frac{1}{n} \sum_{1}^{n} x$ denotes the average (expected value) of a set of data points $x$. In the ideal case of optimal agreement between the variables $A$ and $B$, the measures would reach NSE $=1, \mathrm{KGE}=1, \mathrm{RMSE}=0$, and $\rho=1$.

NSE normalizes the mean squared error by the observed variance, where the mean observed variable $\langle B\rangle$ is used as a baseline. Following this approach, site-specific variations could translate to biased estimation of model skills among different sites. On the other hand, the KGE measure is a revised version of NSE that allows one to analyze the relative importance of the linear correlation $\rho$, variability $\sigma$, and bias $\langle\cdot\rangle$ of simulated and observed variables (Gupta et al., 2009). RMSE is simply a measure of the differences between two time series, but is prone to biased datasets and outliers. The correlation $\rho$ is an accepted approach in experimental geophysics to identify similar or unknown effects (e.g., Fu et al., 2015) in two time series. However, if many factors could explain a single observation, only using the correlation measure may lead to false recognition of coincidental effects.

The KGE is the most appropriate performance measure for time series data as it combines three distinct measures to optimally account for absolute errors and anomalies (compare also Heidbüchel et al., 2016). In the following analysis, we have thus optimized the KGE value between the CRNS and the independent soil moisture data to find a single calibration parameter $N_{0}$ per site.

\section{Study sites}

In order to provide a robust falsification of a potential benefit when using the revised weighted-averaging approach, datasets of six distinct sites have been consulted that offer comparison of the CRNS with independent soil moisture data under various climatic conditions (Fig. 4). At sites 1-2 the CRNS product is calibrated on datasets from so-called calibration campaigns. The term typically refers to one or more days on which soil samples were taken in the field and then analyzed for soil water content in the lab. Sites 3-6 provide time series data from soil moisture monitoring networks 


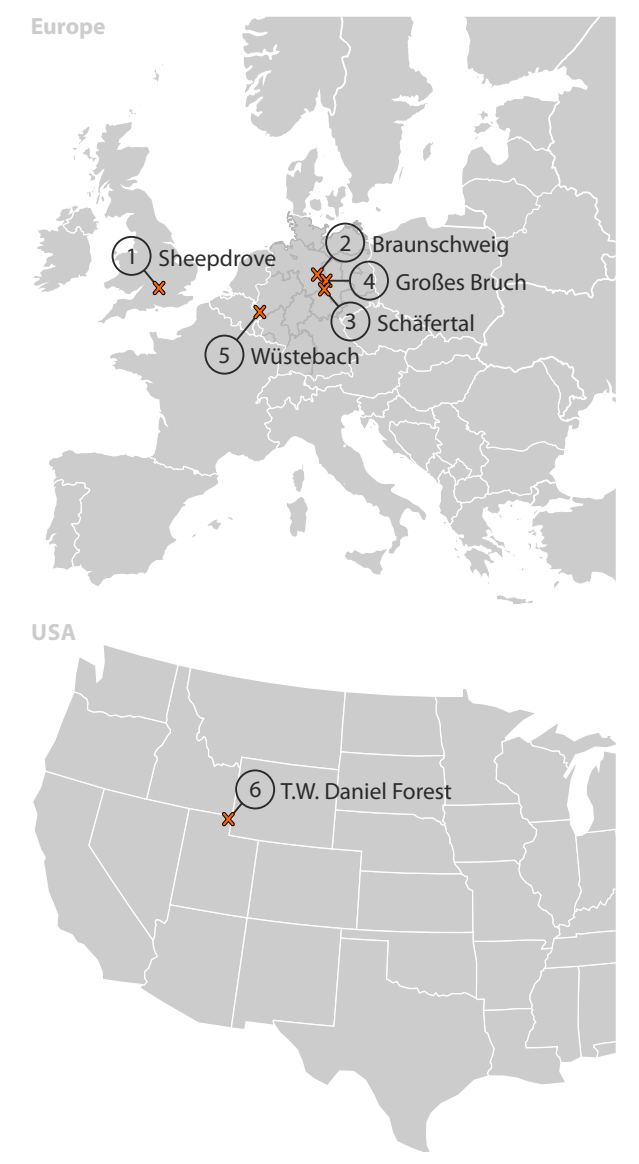

Figure 4. Selection of six distinct observation sites, five across Europe, and one in Utah (US).

(e.g., SoilNet; see also Bogena et al., 2010). These datasets are usually applied to validate the performance of CRNS sensors; however, the present study takes advantage of the continuous recordings in order to calibrate the CRNS probe. Table 1 provides an overview of the site characteristics.

\subsection{The Sheepdrove Organic Farm in Lambourn (UK)}

The Sheepdrove Organic Farm is located at $51.528175^{\circ} \mathrm{N}$, $-1.467311^{\circ} \mathrm{E}, 190 \mathrm{~m}$ a.s.l. in the Lambourn catchment in southern England. This region is characterized by a temperate climate with yearly average precipitation of $815 \mathrm{~mm}$, evenly distributed over the year, and with a mean daily maximum temperature of $14{ }^{\circ} \mathrm{C}$. The CRNS probe is located at a grass strip which exhibits unmanaged soil and vegetation cover. The surrounding field is grazed by sheep during several variable periods throughout the year. During periods of sheep grazing and after harvest the height of the grass outside the strip is a few decimeters lower than within the strip. The soil is loamy clay with many flints and pieces of chalk. Weathered chalk starts at about $25 \mathrm{~cm}$ depth. The groundwater is tens of meters below the surface (Evans et al., 2016).

\subsection{Agricultural site in the lowlands of Braunschweig (GER)}

The second calibration site is an irrigated agricultural field in the northern lowland of Germany near Braunschweig, at an elevation of $60 \mathrm{~m}$ a.s.l. Annual precipitation is $620 \mathrm{~mm}$ and average temperature $9.2^{\circ} \mathrm{C}$. The $12 \mathrm{ha}$ area is irrigated in $50 \mathrm{~m}$ wide strips with pre-treated waste water, as the sandy soils exhibit low water and nutrient holding capacity. The CRNS probe was located in the center of the field $\left(52.3587^{\circ} \mathrm{N}, 10.4004^{\circ} \mathrm{E}\right)$ and several FDR devices provided point measurements of soil moisture. In 2014 the field was cropped with maize (Zea mays) that was ploughed in midApril and harvested on 27 September.

\subsection{The hillslopes and creek in the Schäfertal (GER)}

The Schäfertal intensive monitoring site $\left(11^{\circ} 03^{\prime} \mathrm{E}, 51^{\circ} 39^{\prime} \mathrm{N}\right.$; $395 \mathrm{~m}$ a.s.l.) is an agriculturally used catchment in the middle-mountain area of the Harz mountains in central Germany (Zacharias et al., 2011; Wollschläger et al., 2016). Parts of the hillslope grassland transect are equipped with a wireless soil moisture monitoring network. It has a spatial extent of ca. $240 \times 40 \mathrm{~m}$ and comprises a north- and a south-exposed slope as well as a valley bottom crossed by a creek oriented west to east. Silty-loam Cambisols occupy the slopes, whilst finer-textured and highly organic soils evolved in the riparian zone between the footslope and the creek (Martini et al., 2015).

\subsection{The ponded flood plains at Grosses Bruch (GER)}

The Grosses Bruch research site is a mesophilic grassland used as a meadow, within a nature protection area surrounding the Grosser Graben water channel (52.029728 ${ }^{\circ} \mathrm{N}$, $11.104678^{\circ} \mathrm{E} ; 78 \mathrm{~m}$ a.s.1.) (Wollschläger et al., 2016). The grassland is usually flooded naturally once or twice a year. Soil type in the grassland is a sandy-loamy fluvisol-Gleysol, partly covered with a peat layer of up to $1.5 \mathrm{~m}$ in depth. Eddy covariance measurements of energy, water, carbon dioxide, as well as methane are conducted at the site. Meteorological conditions as well as spatially distributed soil moisture and soil temperature at several depths are observed continuously with a wireless soil moisture monitoring network.

\subsection{The forested Wüstebach catchment (GER)}

The Wüstebach test site is located in the German low mountain ranges within the borders of the Eifel National Park $\left(50^{\circ} 30^{\prime} \mathrm{N}, 6^{\circ} 19^{\prime} \mathrm{E}\right)$ and is part of the TERENO Eifel/Lower Rhine Valley Observatory (Zacharias et al., 2011). The Wüstebach catchment covers an area of $\approx 38.5$ ha with altitudes ranging from $595 \mathrm{~m}$ a.s.l. in the northern part to $628 \mathrm{~m}$ a.s.l. in the southern part. The soil types can be subdivided into terrestrial soils (i.e., Cambisols, Planosols) and semi-terrestrial soils (i.e., Gleysols, Histosols) in the ripar- 
Table 1. Overview of the investigated study sites, their average bulk densities $\left\langle\varrho_{\text {bulk }}\right\rangle$ (in $\mathrm{g} \mathrm{cm}^{-3}$ ), and average volumetric water equivalent $\left\langle\theta_{\text {offset }}\right\rangle$ of additional hydrogen pools (e.g., soil organic carbon, lattice water, root biomass; see Eq. 2).

\begin{tabular}{lllccc}
\hline Site & Period & Description & $\left\langle\varrho_{\text {bulk }}\right\rangle$ & $\left\langle\theta_{\text {offset }}\right\rangle$ & Calibration on \\
\hline Sheepdrove Organic Farm, UK & 2015-2016 & grassland with central strip & 1.16 & 9.0 & 3 sampling days \\
Braunschweig, GER (Scheiffele, 2015) & May-Oct 2014 & irrigation agriculture & 1.49 & 1.0 & 3 sampling days \\
Schäfertal, GER (Martini et al., 2015) & $2012-2013$ & heterogeneous hillslope & 1.15 & 5.2 & time series \\
Grosses Bruch, GER & Aug-Dec 2012 & pasture grassland, floodplain & 1.31 & 10.0 & time series \\
Wüstebach, GER (Bogena et al., 2013) & Apr-Aug 2012 & forested river catchment & 0.83 & 6.7 & time series \\
T. W. D. E. Forest, US (Lv et al., 2014) & Jun-Sep 2012 & complex forest, grass, sage & 1.10 & 4.5 & time series \\
\hline
\end{tabular}

ian zone (Gottselig et al., 2017). The mean porosity of the soils varied from 20 to $81 \%$ for groundwater influenced soils and from 60 to $78 \%$ for the terrestrial soils with decreasing values with increasing depth (Wiekenkamp et al., 2016). In the riparian zone, the water table varied between 0.0 and $1.6 \mathrm{~m}$, while it constantly remained below the soil-bedrock interface outside of the riparian zone (Bogena et al., 2015). The mean annual precipitation was $1220 \mathrm{~mm}$ between 1979 and 1999 and the mean monthly temperature varied from -1.5 to $15^{\circ} \mathrm{C}$ (Bogena et al., 2010). Norway Spruce planted in 1946 is the prevailing vegetation type (Etmann, 2009; Baatz et al., 2014).

\subsection{Complex land use in the T. W. Daniel Experimental Forest (US)}

The T. W. Daniel Experimental Forest lies in the mountaintops in the Wasatch Mountains (IMW), which is one of four components of the Intermountain West of the United States and a transition zone of different climate regimes in both the seasonal and inter-annual timescales. The landscape of the TWDEF site is a patchwork of four domain vegetation communities common to the IMW. Forest communities include aspen and conifer, predominantly Engelmann Spruce, and subalpine fir. Non-forest communities include grasses, forbs, and sagebrush. For each dominant vegetation type, three plots and three subplots within each plot were randomly chosen. Time series data were evaluated from TDT sensors at 10,25 , and $50 \mathrm{~cm}$ and interpolated up to the surface using hydrophysical simulations (Lv et al., 2014).

\section{Results and discussion}

The equal, conventional, and revised weighting approaches have been tested at six distinct research sites. In Sect. 4.1 we have analyzed the calibration datasets at the Sheepdrove Organic Farm and at the Braunschweig site, in order to test the explanatory power of the theoretical relation, $N(\theta)$ (Eq. 1). Section 4.2 discusses the uncertainty related to a time series dataset in the Schäfertal catchment, where the footprint is only partly covered by monitored profiles. Section 4.3 analyzes the potential of CRNS and time series datasets in
Grosses Bruch and Wüstebach to identify additional hydrological processes. At the TWDEF site in Sect. 4.4, we use monitoring profiles in distinct parts of the footprint, which are individually weighted based on their areal contribution to the neutron signal.

\subsection{Improvement of the calibration performance}

In the farmlands of Great Britain, managed fields are often divided by strips of hedges or unmanaged grassland. While unmanaged patches appear to be ideal positions for environmental-monitoring equipment, the presented example shows that CRNS measurements can be biased from the intended information about the field site. Three calibration datasets were collected at various wetness conditions within 9 months. The sampling design was based on the COSMOS standard sampling scheme at 25,75 , and $200 \mathrm{~m}$, plus an additional location at $1 \mathrm{~m}$ near the CRNS probe. Figure 5 demonstrates how the equal (red) and conventional (orange) weightings of the three calibration datasets deviate significantly from the unique theoretical relation $N(\theta)$ (Desilets et al., 2010). By choosing the revised vertical weighting approach (green), the calibration points become much better in line with each other and reveal a unique site-specific calibration curve. One of the reasons is the fact that the conventional approach neglects important parts of the sub-soil layers (beyond $D^{\text {conv }}$ ), as indicated in Fig. $1 \mathrm{~b}$. Additional revised horizontal weighting (blue) leads to a precise match with the theoretical line, supporting the hypothesis that the samples within the strip are most important to the CRNS signal.

As a consequence of the difference between the soil moisture of the grass strip and the surrounding agricultural fields (wetter in summer and drier in winter), the application of a non-weighted calibration leads to significant overestimation or underestimation of the CRNS-apparent soil moisture value, respectively. Furthermore, the experiment clearly shows the importance of a proper positioning of the CRNS probe. If a sensor is dedicated to measuring soil moisture in a certain field, it should be ideally placed in that field. CRNS stations at the field border can be biased by different local characteristics, such as land use or soil properties.

Insights from the British grassland have also been confirmed with calibration datasets from an agricultural site 

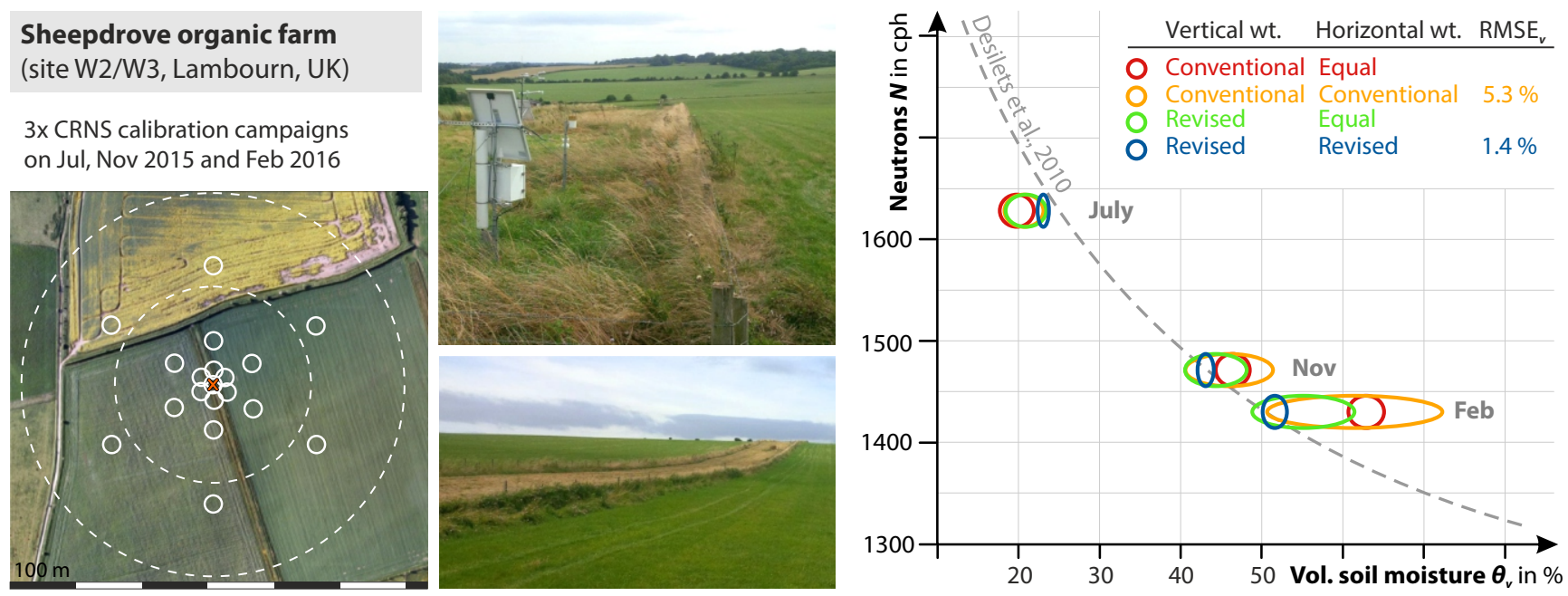

Figure 5. Recalibration of the CRNS sensor in the Sheepdrove Organic Farm (Lambourn, UK) using different combinations of vertically and horizontally weighted averages. Sizes of the circles indicate the corresponding uncertainty range of the measurement. The revised approach clearly removes the bias by the exceptional strip around the sensor, improving the calibration performance with regards to the widely accepted theoretical relation (dashed).
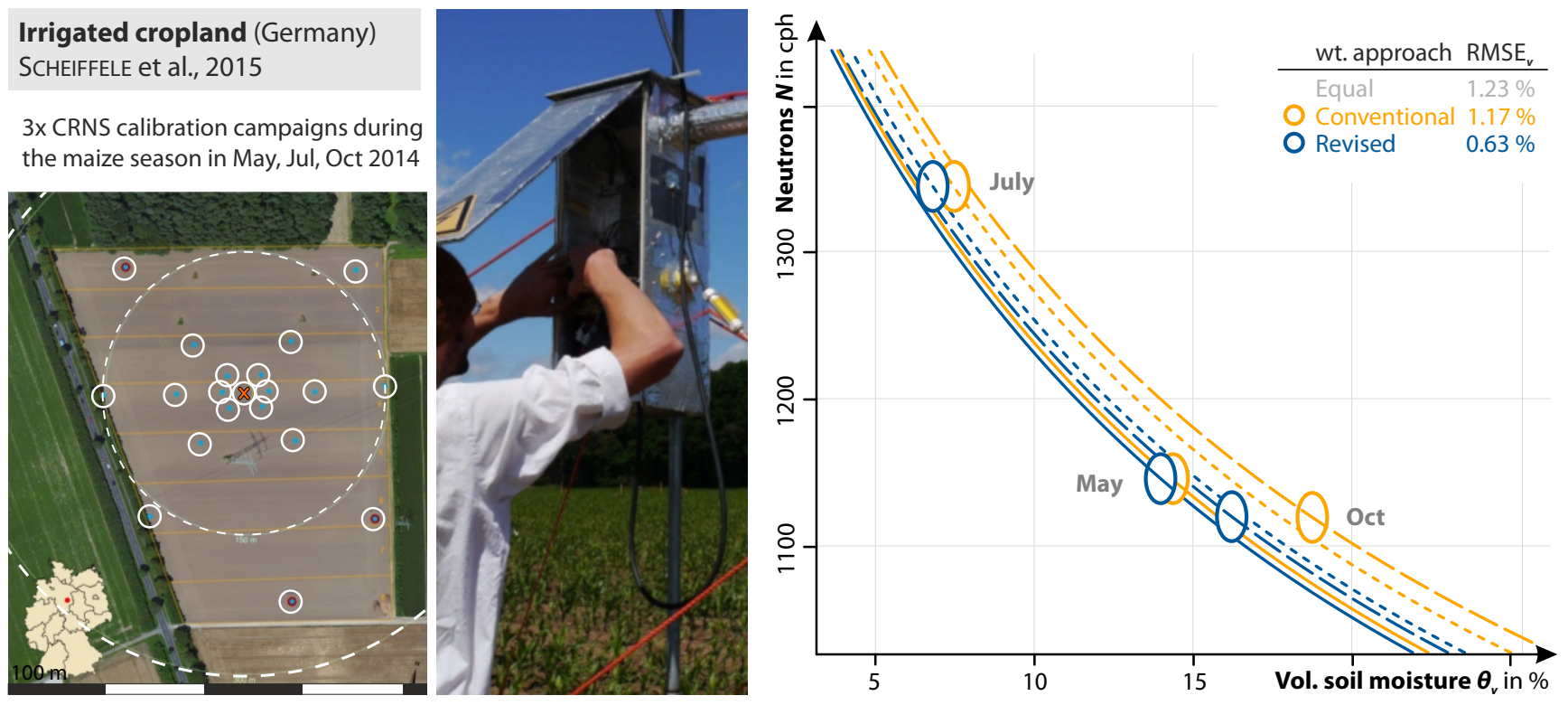

Figure 6. Recalibration of the CRNS sensor in an agricultural maize field (Braunschweig, Germany). Sizes of the circles indicate the corresponding uncertainty range of the measurement, while every such measurement corresponds to a calibration curve $\theta\left(N, N_{0}\right)$. The conventional weighting approach is not able to provide a unique theoretical line through the 3 calibration days. Furthermore, for a given neutron observation the difference between estimated moisture (lines) and actual soil moisture (ellipses) indicates unrealistic biomass dynamics throughout the study period (see explanations in the text). The revised approach converges the datasets to confirm the accepted neutron theory almost in a single calibration curve within uncertainties (size of ellipses).

near Braunschweig. During the agricultural season in 2014, Scheiffele (2015) used the COSMOS standard sampling scheme for three calibration campaigns in May (very small crop, mediocre soil moisture), July (maximum water content in biomass, dry soil), and October (biomass residues after harvest, mediocre soil moisture). The general behavior of the soil moisture dynamics could be reproduced well (Fig. 6), independent of the campaign used for calibration (i.e., determination of $N_{0}$ ). In all three cases, the neutron counts reflect that soil has dried considerably from May to July, to levels below $10 \%$, followed by a period of high precipitation and irrigation that led to increased soil wetness in Octo- 


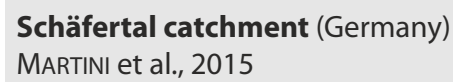

CRNS vs. SoilNet across a hillslope terrain, 2013-2014

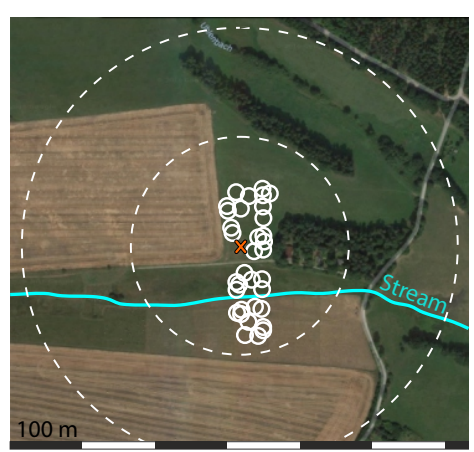

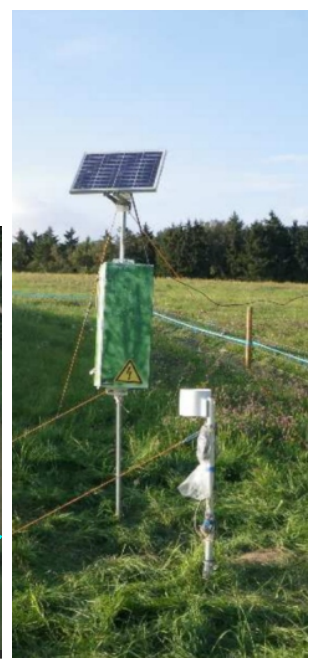

Figure 7. Time series of the CRNS soil moisture data at the SoilNet validation site in Schäfertal (Harz mountains, Germany). The average soil moisture using the conventional weighting approach (orange) exhibits poor performance against the CRNS signal (not shown). The revised approach improves four performance measures of the averaged soil moisture (blue) and the CRNS signal (light blue), although the SoilNet probes are unevenly distributed in the CRNS footprint. The uncertainty of volumetric soil moisture introduced by the insufficient coverage ranges from 1 to $8 \%$ depending on wetness conditions.

ber. However, the performance of the sensor to reflect exact soil moisture states depends on the calibration dataset. Using the conventional averaging approach, the corresponding calibration curves in Fig. 6 (orange lines) indicate a non-unique relationship between neutrons and soil moisture throughout the study period; i.e., hydrogen pools other than soil moisture may have changed, where biomass is the most likely candidate. For example, following the calibration curve from May (solid orange line), the neutron counts detected in July and October would correspond to lower soil water content than actually measured in the field (ellipses); i.e., these neutron observations were higher than expected. This mismatch could be misinterpreted as a reduced amount of biomass in July and October, because decreasing biomass water equivalent usually corresponds to increasing neutron counts (Franz et al., 2013b; Baroni and Oswald, 2015). However, the maize was seeded in May, reached a maximum height in July, and left residues after harvest in October. Therefore, such a conclusion drawn from the conventionally weighted calibration data would be unrealistic.

The data weighted with the revised approach (blue in Fig. 6) demonstrate that the calibration curves converge much closer to a unique theoretical line (Desilets et al., 2010). Their deviation is insignificant given the observational uncertainty of the neutron counter. Although this approach almost removes the unrealistic effect of a seemingly reducing biomass water equivalent, the assumption of a unique calibration parameter $N_{0}$ still does not reflect the expected biomass dynamics in the investigated period. It remains an open question whether a revision of the parameters of Eq. (1) would better catch the local dynamics and would further contribute to the interpretation of the signal. Nevertheless, the example shows that the revised weighting strategy contributes to a more realistic interpretation of the water availability from CRNS measurements, which is especially important when used in conjunction with irrigation management.

\subsection{Uncertainty estimation in a partly covered footprint}

In the Schäfertal intensive monitoring site, a CRNS probe is located in the center of a small area that is covered by a soil moisture monitoring network. The CRNS footprint extends largely beyond this area and involves patches of agricultural land and a nearby forest (Fig. 7). According to the guideline presented in Sect. 2.4 the contribution of the SoilNet area to the neutron signal ranges from $49 \%$ (dry) to $64 \%$ (wet). As a consequence, $36-51 \%$ of the neutron variability does not directly respond to the wetness conditions monitored by the irregularly distributed network. However, in most cases the soil moisture of the outer area can be assumed to correlate with the inner area. As an example case, one could assume an absolute variation of the outer area by $\Delta \theta_{\mathrm{v}}= \pm 5 \%$. Then the uncertainty of the CRNS soil moisture prediction can be further estimated following Sect. 2.4. Under dry conditions $\left(\left\langle\theta_{\mathrm{v}}\right\rangle \approx 15 \%\right)$, the propagated error is $\Delta \theta_{\mathrm{v}}(N) \approx 1-4 \%$, while under wet conditions $\left(\left\langle\theta_{\mathrm{v}}\right\rangle \approx 35 \%\right)$, the neutron counts are less sensitive to soil moisture changes in the outer area due to the smaller footprint (Köhli et al., 2015). This leads to $\Delta \theta_{\mathrm{v}}(N) \approx 4-8 \%$. Therefore, calibration results that resulted in an $\mathrm{RMSE}_{\mathrm{v}}$ of $\approx 4 \%$ (Fig. 7) are not meaningful under wet conditions (where $\Delta \theta(N) \geq 4 \%$ ) , and are still uncertain un- 

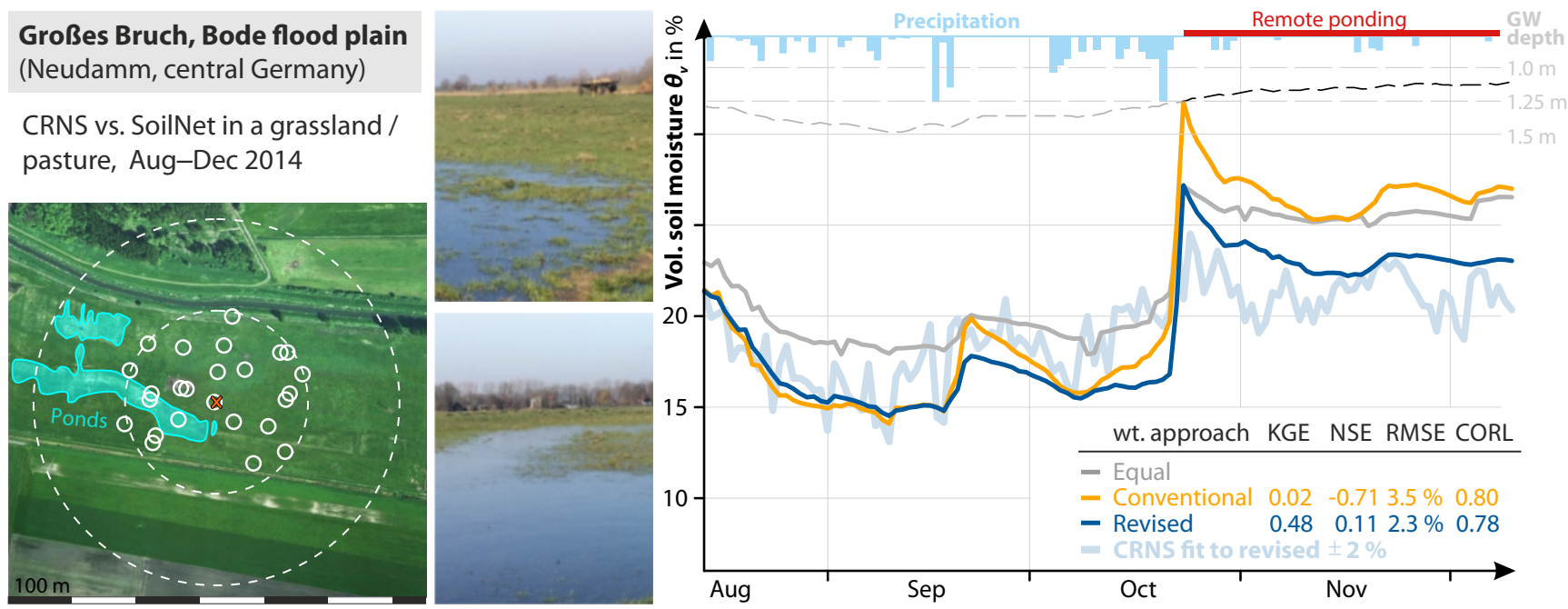

Figure 8. Time series of soil moisture measured in a pasture/floodplain - Grosses Bruch. The rain events in mid-October 2014 lead to a rise in the groundwater level and ponding in regions that are several tens of meters away from the neutron sensor. In that period, equal and conventional weighting leads to overestimation of apparent soil moisture near the CRNS probe, to which the detector has higher sensitivity than to the remote ponds.

der dry conditions (where $\Delta \theta_{\mathrm{v}}(N) \leq 4 \%$ ). Consequently, the partial coverage of the CRNS footprint by the irregularly distributed SoilNet hampers the proper evaluation of the CRNS data, and especially of the weighting strategies.

Nevertheless, the Schäfertal data show that the revised weighting approach is robust enough to improve the overall CRNS performance (Fig. 7), even though the sensor is situated in complex terrain where the SoilNet sampling locations are not representative of the CRNS footprint. As the revised approach shows the best accuracy in all four statistical measures, the $\mathrm{RMSE}_{\mathrm{v}}$ is still higher than the measurement error of the daily mean $(\approx 2 \%)$. This indicates that deviations can be attributed (1) to the insufficient coverage of the SoilNet, and (2) to different processes in different parts of the footprint (speculative examples are vegetation growth, forest water interception, snow accumulation, evapotranspiration, plowing, etc.).

\subsection{Identification of additional hydrological processes}

The Grosses Bruch pasture site is a good example of how an inappropriate averaging approach could hinder sufficient interpretation of time series data. Figure 8 shows the soil moisture signal predicted from a stationary CRNS probe and the weighted signal of a soil moisture monitoring network (SoilNet) with sensors installed at depths from 0.05 up to $0.6 \mathrm{~m}$. Following the precipitation events in the second half of October, the shallow groundwater and loamy texture allowed large water ponds to reside permanently in the outer regions of the SoilNet (light blue indication on the map). As distant areas contribute much less to the CRNS signal than closer ones, the revised weighting approach has significantly reduced the influence of the saturated point data on the apparent CRNS average. Without the revised method, the CRNS product would have overestimated the absolute volumetric field saturation by more than $5 \%$. Additionally, beginning in the middle of September, many cows had been present at this site, which are assumed to have led to large variations of the neutron signal and thus to a non-meaningful expression of correlation-related measures.

In the Wüstebach forest site, weighted averaging of the soil moisture monitoring network is performed based on the data presented in Bogena et al. (2013). The analysis shows three interesting effects on the resulting soil moisture signal in Fig. 9. Firstly, the signal processed with the revised weighting approach (blue) is wetter than the conventionally weighted signal (orange). This effect is reasonable due to the higher soil water contents of the groundwater-influenced riparian zone, where the CRNS is located, compared to the terrestrial soils at the hillslopes. Secondly, the CRNS signal which was calibrated to the revised weighted soil moisture (light blue) outperforms the signal that was calibrated on the conventionally weighted soil moisture (light orange). This performance gain is robust in terms of the four measures. In order to avoid incorrect conclusions from overcalibration of the data during rain events (periods of high interception water), we repeated the same analysis for dry periods only. In this case the revised approach again led to the highest performance (not shown) and confirmed the robustness of this approach. Thirdly, differences between CRNS and SoilNet appear to be significantly more prominent for the revised approach (blue) in periods following huge precipitation events (May, July, and October). Those periods can probably be attributed to expected canopy water storage, interception stor- 


\section{Wüstebach forest valley \\ (Germany), BOGENA et al., 2013}

CRNS vs. SoilNet in a forested river catchment, Apr-Oct 2012

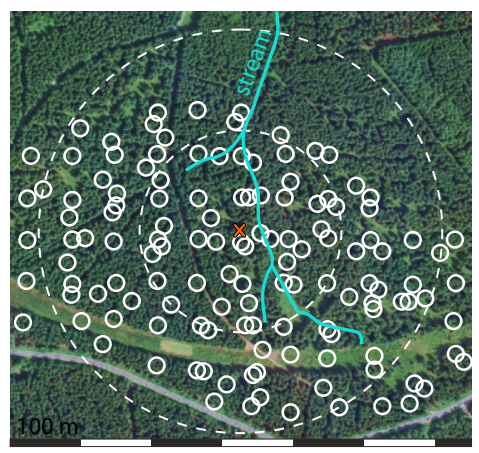

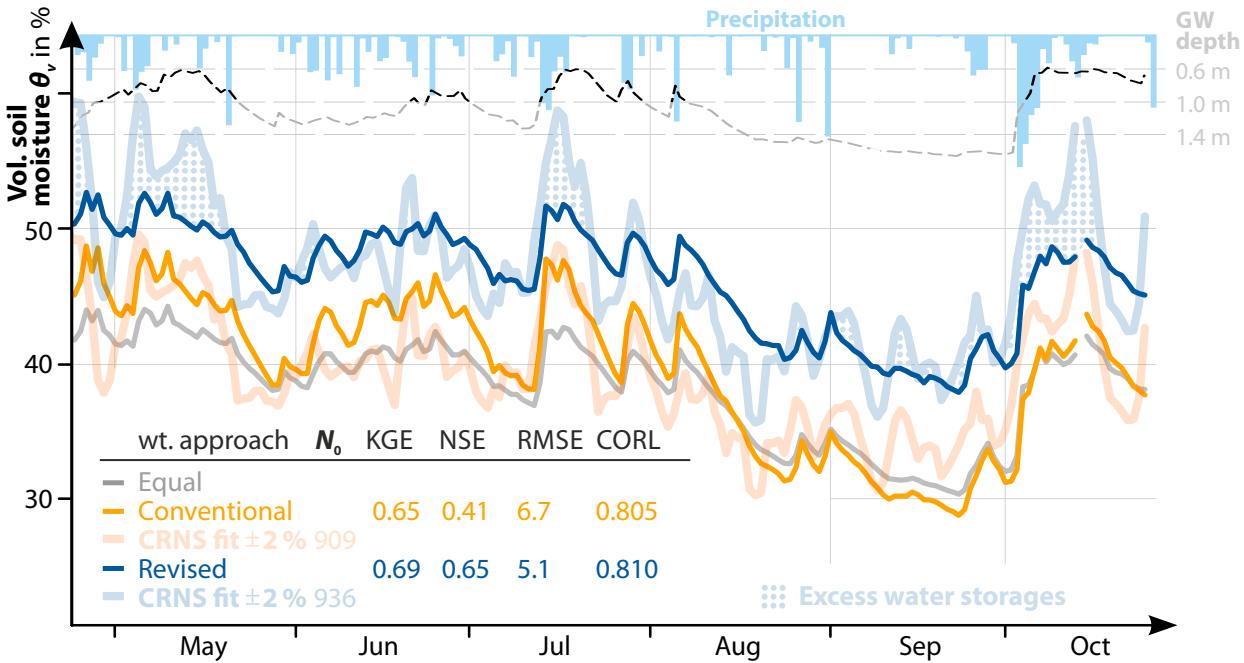

Figure 9. Time series of CRNS soil moisture and groundwater at the Wüstebach forested river catchment. Fitting the CRNS data to the SoilNet conventional average almost completely hides effects from excess water storages (which could include water in the litter layer, interception water, groundwater rise, or ponding close to the stream). The revised approach emphasizes those additional hydrological processes while still robustly increasing the sensor performance.

age, groundwater rise, and nearby accumulation of ponds. Ponded water in local hollows, trenches, and the litter layer are not visible in the soil profiles of the monitoring network, which are typically installed in solid and elevated ground. In contrast, their effect can be visible in stronger oscillations and shifts of the CRNS signal.

The analysis demonstrates that the revised weighting of calibration data is essential to identify residual hydrological effects which otherwise can get lost by overfitting. By comparing CRNS data and point measurements, residual information could be used to identify additional processes like biomass dynamics or rainfall interception (Baroni and Oswald, 2015). The methods presented here can support efforts to identify those residuals to a much higher precision. In order to properly quantify the excess water storages in future studies, we would recommend calibrating the CRNS signal only in periods when the site had not been exposed to rain events for a few consecutive days. In the case of the Wüstebach site (Fig. 9), this would lift the deviations of the CRNS signal (light blue) up from below the averaged soil moisture (blue) and would thus properly highlight the added water to the system.

\subsection{Areal contribution of distinct land-use classes}

Lv et al. (2014) analyzed the CRNS performance in the center of a complex mixture of grass and sage land, surrounded closely by an aspen and conifer forest located in the north of Utah (US). The authors took continuous TDT measurements in all four of those land-use types, complemented the dynamics of the soil moisture profiles with the help of HYDRUS-1D simulations, and found decent correlation with the CRNS signal (compare also similar approaches by Rivera Villarreyes et al. (2011) in a farmland). It is interesting to note that each of the four land-use compartments actually behaved very differently in terms of soil water dynamics, depicted as dotted lines in Fig. 10.

As each compartment is distributed differently in the CRNS footprint, the contribution of each area is different and thus cannot be averaged adequately by a simple weighting approach. However, in contrast to the complex terrain of the Schäfertal site (Sect. 4.2), here all land-use and soil types are represented by adequate sample locations. We therefore grouped the soil moisture information of the four compartments, and weighted each $1 \mathrm{~m}^{2}$ pixel of the areal contribution map depending on the pixel's distance $r$ to the CRNS probe (see the last paragraphs of Sect. 2.3). This strategy again showed improved CRNS performance for all measures (black dashed line in Fig. 10) compared to the simple approach of weighting only the individual monitoring points (orange and blue solid lines). Although the gained performance is not significant in the light of the measurement uncertainty, this areal weighting approach can be suggested as the most realistic representation of the contribution of heterogeneous soil moisture patterns to the CRNS signal.

\subsection{Towards a revised sampling scheme}

The presented results raise the question whether it could be profitable to apply a $W_{r}$-flavored sampling design to the locations used for calibration and validation. Based on Zreda et al. (2008), the conventional weighting function $W_{r}^{\text {conv }}$ laid the basis for the COSMOS standard sampling scheme, $R_{i}=\{25,75,200 \mathrm{~m}\}$ (Franz et al., 2012a). These radii were 

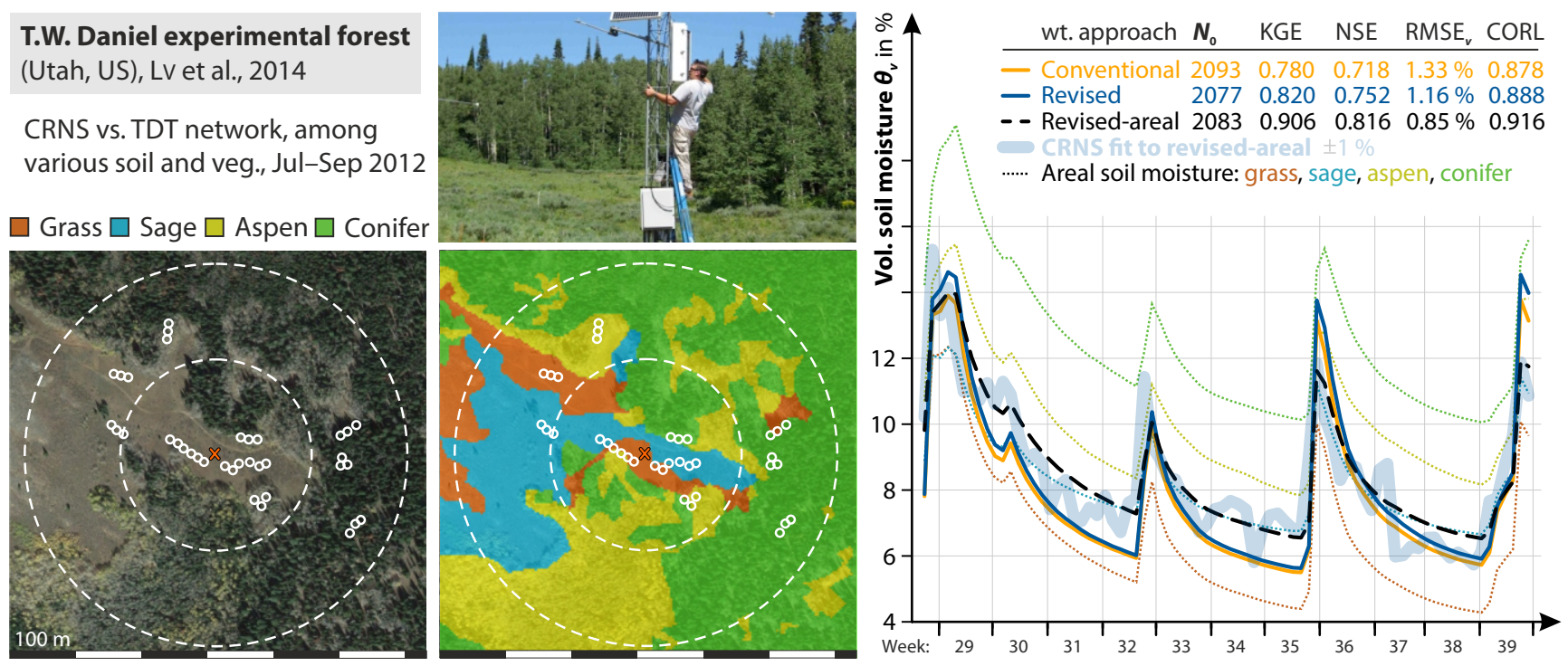

Figure 10. Time series of CRNS and TDT soil moisture at the T. W. Daniel Experimental Forest. The area was split into four categories (dotted lines), to which the corresponding soil moisture measurements were assigned. The areal coverage was then averaged (dashed line) pixel by pixel ( $1 \mathrm{~m}$ resolution) with the revised weighting approach, leading to the best performance against the CRNS signal.

located in the $33 \%$ quantiles of the footprint (see also Bogena et al., 2013, Table 3):

$\frac{1}{3} \int_{0}^{\infty} W_{r}^{\mathrm{conv}} \approx \int_{0}^{48} W_{r}^{\mathrm{conv}} \approx \int_{48}^{142} W_{r}^{\mathrm{conv}} \approx \int_{142}^{\infty} W_{r}^{\mathrm{conv}}$.

As Köhli et al. (2015) introduced the revised weighting function $W_{r}(h, \theta)$, the standard sampling scheme has become inappropriate, at least in non-homogeneous terrain, for two reasons: (1) the revised sensitivity is steeper, particularly at short distances to the probe, and (2) depends on the total water equivalent of the surrounding hydrogen pools. In particular, the dynamical horizontal weighting has been applied here to demonstrate its ability to significantly improve CRNS performance. While existing data from point sensor networks could be re-weighted in post-processing mode, the question arises whether positioning schemes for upcoming soil moisture networks or calibration campaigns could adapt to the nature of neutron physics to maximize comparability.

Obviously, it is impossible to provide a new general position plan, due to the temporal variability of $W_{r}$ and $W_{d}$, and the heterogeneity of local structures and conditions. Instead, selection of sampling locations should depend on (1) their representativeness for local features and (2) their distance to the sensor. In general, it can be recommended to select a significant portion of available sampling points within the nearest $25 \mathrm{~m}$, since $30-50 \%$ of detected neutrons typically originated in that area. The conventional sampling scheme from Franz et al. (2012a) does not account for this contribution, which is particularly relevant if local correlation lengths of soil moisture can be below 20-30 m. The number of samples in an area should also represent its areal contribution to the neutron signal, in order to reduce measurement uncertainty in areas where the CRNS probe is most sensitive. This argumentation justifies a lower amount of samples in regions far afield.

To give further advice on a reasonable distribution of points for homogeneous terrain, sampling radii $R_{i}$ of concentric circles could be calculated as follows. First, select a total number of circles $n$ based on prior knowledge about the patterns at the individual site. Since the signal contribution of an area between any radii can be calculated by integrating $W_{r}$ (compare also Köhli et al., 2015, Eq. 1), the $n$ borders of equal areal contribution, $r_{i}, i \in(1, \ldots, n)$, can be calculated by solving the integral:

$$
\int_{0}^{r_{i}} W_{r^{*}}(h, \theta) \mathrm{d} r^{*} \stackrel{!}{=} \frac{i-1}{n} \int_{0}^{\infty} W_{r^{*}}(h, \theta) \mathrm{d} r^{*} .
$$

Then, the sampling radii $R_{i}$ can be selected anywhere between $r_{i}$ and $r_{i+1}$, as they are assumed to represent the area of the corresponding homogeneous annulus. A simple guideline could be to set the sampling radius in the geometrical center:

$R_{i}\left(h, \theta, p, H_{\mathrm{veg}}\right)= \begin{cases}r_{i}+0.5\left(r_{i+1}-r_{i}\right), & i<n, \\ r_{i}+0.5 r_{i}, & i=n,\end{cases}$

where the last sampling distance $R_{n}$ could be set to any point that is expected to represent the whole area beyond $r_{n}$. 

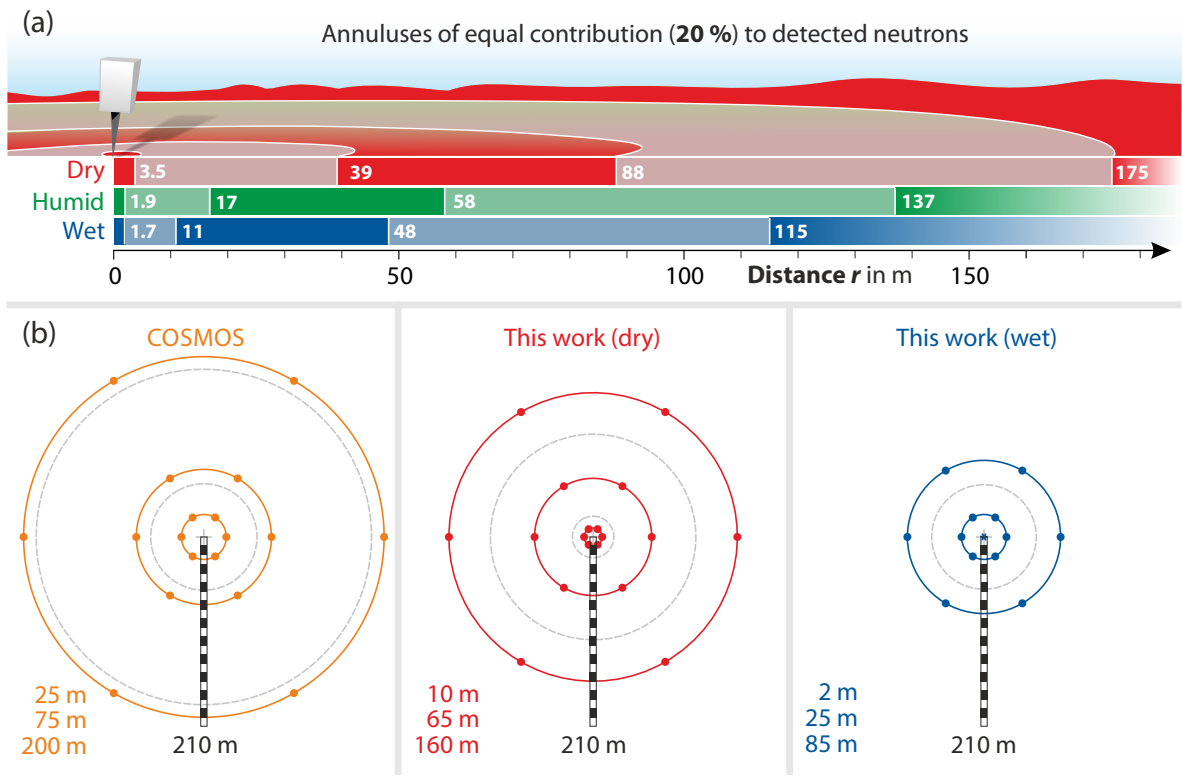

Figure 11. (a) Illustration of regions of equal contribution (20\% quantiles) to the neutron signal for three climates, $h=\{2,7,20\} \mathrm{g} \mathrm{m}^{-3}$, $\theta_{\mathrm{v}}=\{2,20,50\} \%$. (b) The COSMOS standard sampling scheme based on $W_{r}^{\text {conv }}$, compared to two exemplary three-radii schemes based on the revised function $W_{r}$ for dry $\left(h=1 \mathrm{~g} \mathrm{~m}^{-3}, \theta_{\mathrm{v}}=1 \%\right)$, and wet $\left(h=10 \mathrm{~g} \mathrm{~m}^{-3}, \theta_{\mathrm{v}}=40 \%\right)$ conditions. Circles represent the borders of the $33 \%$ quantiles, $r_{i}$ (grey, dashed), and arbitrary sampling distances $R_{i}$ within these annuluses (colored, solid).

As an example for $n=5$, Fig. 11a illustrates five annuluses of the footprint area which equally contribute to the neutron signal. Based on this picture, an equal number of sampling locations is recommended in each annulus. For example, if it is desired to use the hitherto proposed number of 18 locations for humid conditions, 3 could be distributed within $2 \mathrm{~m}$ distance, another 3 within $17 \mathrm{~m}$, and the remaining 12 locations evenly within 58,137 , and $240 \mathrm{~m}$, respectively. In order to compare this approach with the conventional sampling scheme by Franz et al. (2012a), a three-annulus scheme can be adapted from Eq. (7):

dry : $\frac{1}{3} \int_{0}^{\infty} W_{r^{*}} \approx \int_{0}^{24} W_{r^{*}} \approx \int_{24}^{108} W_{r^{*}} \approx \int_{108}^{\infty} W_{r^{*}}$,

wet : $\frac{1}{3} \int_{0}^{\infty} W_{r^{*}} \approx \int_{0}^{4} W_{r^{*}} \approx \int_{4}^{61} W_{r^{*}} \approx \int_{61}^{\infty} W_{r^{*}}$.

Thus, if $n=3$ radii are desired for the sampling scheme, a possible (but arbitrary) suggestion could be $R_{i}^{\text {dry }} \approx\{10,65$, $160 \mathrm{~m}\}$ and $R_{i}^{\text {wet }} \approx\{2,25,85 \mathrm{~m}\}$, as illustrated in Fig. $11 \mathrm{~b}$ (compare also Heidbüchel et al., 2016, Sect. 4.2).

This arrangement, however, should not relieve scientists of weighting their data in post-processing mode, because each annulus still exhibits a sensitivity gradient. But the $20 \%$ annulus method strongly concentrates locations within most relevant regions favored by detectable neutrons. It is also worth noting that locations need not be equally distributed among the annuluses. The actual partitioning should rather be guided by expert knowledge about local patterns, ideally including spatial distributions of soil characteristics and land use. Proper weighting of sampling data in post-processing can be helpful to compensate for the lack of such information. Given entirely homogeneous soil, for instance, a single location would do.

Is this strategy still robust against complex terrain and variable weather? Field sites differ in terms of spatial heterogeneity and variability due to terrain features or highly heterogeneous correlation lengths of soil moisture patterns. Hence, implementing a strict, universal sampling scheme often is neither feasible nor meaningful with regards to individual conditions in the field. In this study the application of the revised weighting approach led to improved CRNS performance at all sites and for regular and irregular sampling designs. Apparently, the presented weighting procedure is robust across various sites, sampling configurations, and wetness conditions.

An advantage of the approach is its straightforward applicability, which essentially applies a simple distanceweighted average to a set of data points, and does not require additional, complex analysis or interpolation strategies. The only assumption made is that each sample point represents an equal area in the footprint. Apart from sophisticated optimal sampling designs, three of the most simple sampling strategies are (1) regular grids, (2) random locations, and (3) locations that represent stable patterns (of soil moisture or land cover). However, judgment about their performance 
Table 2. Summary of the CRNS performances achieved by changing from the conventional to the revised weighting approach. RMSE $\mathrm{V}_{\mathrm{V}}$ is in units of volumetric \%. CRNS data have been calibrated on 3 sampling days (sites 1-2) or on time series of a soil moisture monitoring network (sites 3-6). The revised weighting approach improved the performance at all sites, and helped to identify additional hydrological features.

\begin{tabular}{lcrcll}
\hline Site & KGE & NSE & RMSE $_{\mathrm{v}}$ & Correlation & Note \\
\hline Sheepdrove Organic Farm, UK & & & $5.3 \rightarrow 1.4$ & & bias from grass strip \\
Braunschweig, GER & & & $1.2 \rightarrow 0.6$ & & data became more consistent \\
Schäfertal, GER & $0.88 \rightarrow 0.93$ & $0.81 \rightarrow 0.87$ & $4.0 \rightarrow 3.3$ & $0.92 \rightarrow 0.94$ & incomplete SoilNet coverage \\
Grosses Bruch, GER & $0.02 \rightarrow 0.48$ & $-0.71 \rightarrow 0.11$ & $3.5 \rightarrow 2.3$ & $0.80 \rightarrow 0.78$ & remote ponding \\
Wüstebach, GER & $0.65 \rightarrow 0.69$ & $0.41 \rightarrow 0.65$ & $6.7 \rightarrow 5.1$ & $0.80 \rightarrow 0.81$ & revealed excess water storages \\
T. W. D. E. Forest, US & $0.78 \rightarrow 0.91$ & $0.72 \rightarrow 0.82$ & $1.3 \rightarrow 0.8$ & $0.88 \rightarrow 0.92$ & areal weighting of 4 clusters \\
\hline
\end{tabular}

is far beyond the scope of this work. In any case, it could be recommended to reduce the uncertainty of samples close to the detector (e.g., by taking repeated measurements), because neutron theory has shown that the CRNS signal is most sensitive to nearby locations.

A simple and pragmatic way to design a reasonable sampling scheme could be to choose sensor locations based on the approximated horizontal sensitivity function $W_{r}^{*}$ (Appendix B). As this function does not depend on dynamic changes in surrounding hydrogen pools, an equal average would be sufficient in post-processing mode. However, the dependence on air humidity $h$ and soil moisture $\theta$ will introduce temporal errors to this approach. In this case it could be recommended to correct the equal average with its dynamic variability, which can be expressed as the variation of $W_{r}(h$, $\theta$ ) around its mean, $W_{r}^{*}$.

To circumvent a potential bias introduced by arbitrarily distributed locations, it could be better to apply different zonation approaches or interpolation methods (e.g., Kriging in polar coordinates) before each cell of the interpolated grid is weighted. However, this always comes with additional assumptions. For example, in the sampling strategy presented in Sect. 4.4 certain soil moisture patterns in the field were categorized as four areas of different land uses which were expected to behave equally in the footprint in terms of soil water dynamics. The horizontal weighting was then applied to those measurements depending on the location of the contributing area in the footprint. In our opinion this method probably provides the highest accuracy in most cases, although it requires prior knowledge about the distribution of soil type compartments in the footprint.

This study has focused on the theory and application of the averaging approach, while the performance of different interpolation strategies might depend on local soil patterns and deserves a study on its own, for their performance always depends on the local structures and correlation lengths of soil moisture.

\section{Conclusions}

In this paper a general procedure for horizontal and vertical weighting of point measurements has been presented in order to calibrate and validate the CRNS soil moisture product. The method is based on revised spatial sensitivity functions (or weighting functions) from neutron physics simulations (Köhli et al., 2015). Notably, the revised functions have been further advanced in the present work with an updated version of the URANOS neutron transport code, by adding dependency on air pressure and vegetation height, and by extending the analysis to distances below $0.5 \mathrm{~m}$. The performance of the conventional weighting functions has been compared with the revised functions using datasets from a variety of distinct sites located in Germany, the UK, and the US. The improvements of the CRNS performances for each site are summarized in Table 2, including a note that highlights specific features of the analyses.

The study has led to the following conclusions.

1. The revised averaging of observed point data improved the performance measures of the CRNS product for all investigated sites when compared with the equal and conventional approaches. The method is thus applicable to arbitrarily distributed sampling locations without prior knowledge of soil and land-use features.

2. The results show that unrealistic deviations of multiple calibration datasets from the theoretical line can be removed by applying the revised weighting functions. Thus they support the original hypothesis by Desilets et al. (2010) of a single calibration campaign to capture the local soil moisture dynamics. The approach can thus substantially reduce the calibration efforts for CRNS probes, in contrast to recent findings from Iwema et al. (2015) and Heidbüchel et al. (2016).

3. Although existing data can be weighted in postprocessing mode, missing locations close to the detector as well as insufficient coverage of the CRNS footprint introduce significant uncertainty. It can be quantified with the help of the radial sensitivity functions, as has been presented in Sects. 2.4 and 4.2. 
4. Sampling strategies that are based on concentric rings can only be recommended for homogeneous terrain (where each sampling location is known to contribute equally to the signal) and should be adapted on the local site conditions (air pressure, humidity, soil moisture, vegetation cover). If the samples are arranged according to Eq. (8), their equally weighted average would provide a value that is comparable to the CRNS product. On the other hand, if the footprint is covered by heterogeneous soil and land-use patterns, the sample locations should be adapted to distinct representative clusters, which in turn should then be weighted based on their areal contribution to the signal (see Sect. 4.4).

5. Data points in the first 0 to $10 \mathrm{~m}$ radius and 0 to $20 \mathrm{~cm}$ depth around the sensor are most important for calibration and validation purposes. It is thus recommended to reduce the uncertainty of those measurements, e.g., by increasing the number of samples in that area.

6. As previous studies have shown, the CRNS soil moisture signal could be calibrated to match the simple, equal average of the areal soil moisture in the footprint. However, important hydrological features could be missed by doing so and data interpretation might become misleading. When CRNS is combined with independent soil moisture measurements, the revised weighting approach has the potential to reveal hydrological features that were otherwise lost in the signal by overcalibration. The approach improved the accuracy by which the CRNS probe was able to sense total changes in water storages other than soil moisture, e.g., from water in the biomass or litter layer, interception water, groundwater rise, as well as ponding in remote or local areas.

The revised weighting functions presented here are provided in the Supplement in R, MATLAB, and Excel (see Appendix $C$ ). Furthermore, an approximated weighting function $W_{r}^{*}$ (Appendix B) has been suggested to simplify quick analysis of the horizontal contributions independently of the local wetness conditions. However, the latter approach should be taken with care, for its adequate performance has not been sufficiently confirmed in this work.
Within this study many datasets have been reanalyzed to test the revised weighting approach. Due to its overall success, it is recommended to also revisit other studies, especially where the conventional approaches have not led to the expected results (e.g., Franz et al., 2012a; Almeida et al., 2014; Iwema et al., 2015). In the light of the discussion provided, we recommend future studies to improve the sensor performance even further, for example, by investigating the effect of different sampling designs and interpolation strategies or by recalibrating the parameters of the theoretical line, $N(\theta)$. Specific URANOS simulations of the neutron distribution at the individual sites can further help to identify the contribution to the detector signal of different parts in the footprint.

On the basis of the results gained by this study and in the light of the conclusions above, it can be deduced that CRNS stations placed in mostly homogeneous terrain offer the highest interpretability of its field-scale signal. This is a feature that the CRNS method has in common with many other hydrometeorological instruments, like weather stations (Jarraud, 2008) or eddy covariance towers (Rebmann et al., 2005). However, even in complex terrain CRNS probes are capable of catching hydrogen pools that otherwise would be very difficult to monitor (e.g., ponding, interception), while their sensitivity to specific parts of the footprint can be quantified with the help of $W_{r}$. Thereby, the present study demonstrates a way forward to a better understanding of the spatial contributions to the neutron signal, and elaborates the potential of cosmic-ray neutron sensors to quantify hydrological features that are almost impossible to be caught with conventional instruments.

Data availability. Data from the Sheepdrove Organic Farm are available upon request. Data from Grosses Bruch will soon be available in the TERENO Data Discovery Portal (http://teodoor. icg.kfa-juelich.de/ibg3searchportal2/index.jsp). Data from Braunschweig, Schäfertal, Wüstebach, and T. W. D. E. Forest are available from the given references (see Table 1). 


\section{Appendix A: The revised weighting functions}

Köhli et al. (2015) did not discuss in detail the dependencies of the weighting functions $W_{r}$ and $W_{d}$ on air pressure and humidity, although they made it clear that these quantities have a significant influence on the footprint radius. For this reason additional analysis has been performed to investigate the dependency of the sensitivity functions on other environmental variables, and relations have been found that do not make the analytical formulations of $W_{r}$ and $W_{d}$ more complex. The weighting functions can easily adapt to variations of air pressure $p$ and vegetation height $H_{\text {veg }}$ by scaling their argument $r$ with the scaling rules of the footprint radius $R_{86}$ (cf. Köhli et al., 2015, Eqs. 4-6):

$W_{r}\left(h, \theta, p, H_{\mathrm{veg}}\right) \approx W_{r^{*}}(h, \theta)$

and

$W_{d}\left(\theta, r, p, H_{\mathrm{veg}}\right) \approx W_{d}\left(\theta, r^{*}\right)$,

where

$r^{*}\left(r, p, H_{\mathrm{veg}}, \theta\right)=r / F_{p} / F_{\mathrm{veg}}\left(H_{\mathrm{veg}}, \theta\right)$.

Figure A1 shows that this approximation performs well for various wetness conditions, as simulated curves and pressure-adapted curves are almost parallel (relative agreement is sufficient as weighting functions typically perform in a relative mode).

Moreover, the data analysis in this work sometimes requires realistic weights to be applied for samples located within $r<0.5 \mathrm{~m}$, which is by definition an invalid range for $W_{r}(h, \theta)$ as reported by Köhli et al. (2015). We therefore felt the need to extend the horizontal weighting function to the range below $0.5 \mathrm{~m}$. In this work, we introduced an additional exponential factor in Eq. (6) which accounts for the steep increase near the detector. This peak has geometrical reasons and essentially comes from the fact that (1) only a few neutrons can originate from small radii $\left(W_{r \rightarrow 0} \rightarrow 0\right)$, and (2) the neutrons coming from higher radii have a lower chance of hitting the detector $\left(W_{r \rightarrow \infty} \rightarrow 0\right)$.

The following parameter functions apply to the updated weighting functions (compare also Köhli et al., 2015, Appendix A):

$$
\begin{aligned}
& F_{0}=p_{0}, \\
& F_{1}=p_{0}\left(1+p_{3} h\right) e^{-p_{1} \theta}+p_{2}\left(1+p_{5} h\right)-p_{4} \theta, \\
& F_{2}=\left(\left(p_{4} h-p_{0}\right) e^{-\frac{p_{1} \theta}{1+p_{5} \theta}}+p_{2}\right)\left(1+p_{3} h\right),
\end{aligned}
$$

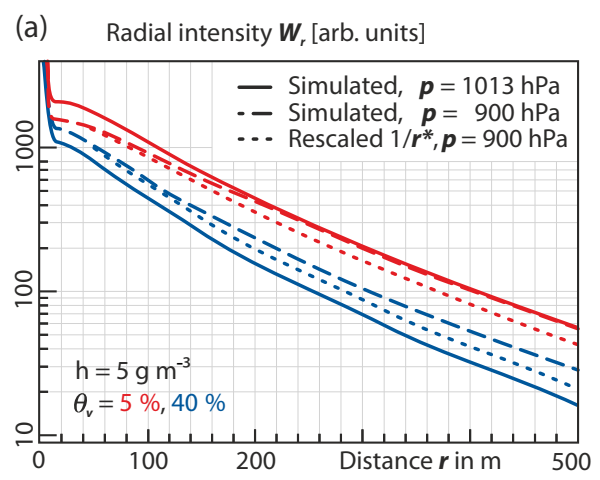

(b) Radial intensity $\boldsymbol{W}_{\boldsymbol{r}}$ [arb. units]

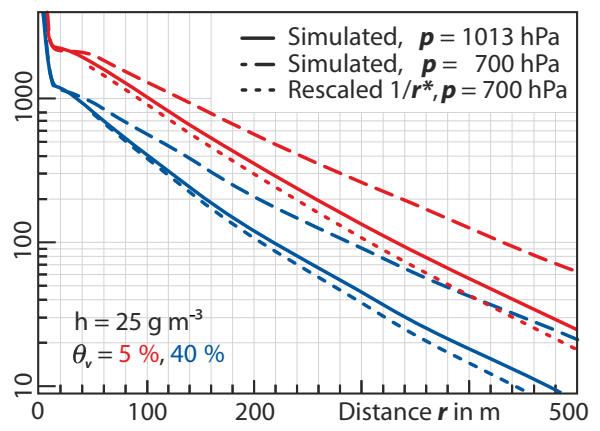

Figure A1. Pressure dependence of the weighting function $W_{r}$ demonstrated for two cases of air pressure and humidity. The rescaled $p$-adapted curves (dots, Eq. A1) are almost parallel to the non-adapted curves (solid), indicating that the normlized weight leads to the same results. (a) Dry midlands; (b) humid highlands.

$$
\begin{aligned}
& F_{3}=p_{0}\left(1+p_{3} h\right) e^{-p_{1} \theta}+p_{2}-p_{4} \theta, \\
& F_{4}=p_{0} e^{-p_{1} \theta}+p_{2}-p_{3} \theta+p_{4} h, \\
& F_{5}=\left(p_{0}-\frac{p_{1}}{p_{2} \theta+h-0.13}\right)\left(p_{3}-\theta\right) e^{-p_{4} \theta}-p_{5} h \theta+p_{6}, \\
& F_{6}=p_{0}\left(h+p_{1}\right)+p_{2} \theta, \\
& F_{7}=\left(p_{0}\left(1-p_{6} h\right) e^{-p_{1} \theta\left(1-p_{4} h\right)}+p_{2}-p_{5} \theta\right)\left(2+p_{3} h\right), \\
& F_{8}=\left(\left(p_{4} h-p_{0}\right) e^{\frac{-p_{1} \theta}{1+p_{5} h+p_{6} \theta}}+p_{2}\right)\left(2+p_{3} h\right), \\
& F_{p}=p_{0} /\left(p_{1}-e^{-p / 1013 \mathrm{mbar}}\right), \text { air pressure } p, \\
& F_{\mathrm{veg}}=1-p_{0}\left(1-e^{-p_{1} H_{\mathrm{veg}}}\right)\left(1+e^{-p_{2} \theta}\right), \text { vegetation height } H_{\mathrm{veg}}, \\
& D_{86}=\frac{1}{\varrho_{\text {bulk }}}\left(p_{0}+p_{1}\left(p_{2}+e^{-p_{3} r^{*}}\right) \frac{p_{4}+\theta}{p_{5}+\theta}\right), \text { scaled distance } r^{*} .
\end{aligned}
$$


Table A1. Parameters for the horizontal weighting function, the adapted distance scaling, and the effective penetration depth (Appendix A).

\begin{tabular}{lrrrrrrr}
\hline & $p_{0}$ & $p_{1}$ & $p_{2}$ & $p_{3}$ & $p_{4}$ & $p_{5}$ & $p_{6}$ \\
\hline$F_{0}$ & 3.7 & & & & & & \\
$F_{1}$ & 8735 & 22.689 & 11720 & 0.00978 & 9306 & 0.003632 & \\
$F_{2}$ & 0.027925 & 6.6577 & 0.028544 & 0.002455 & $6.851 \times 10^{-5}$ & 12.2755 & \\
$F_{3}$ & 247970 & 23.289 & 374655 & 0.00191 & 258552 & & \\
$F_{4}$ & 0.054818 & 21.032 & 0.6373 & 0.0791 & $5.425 \times 10^{-4}$ & & \\
$F_{5}$ & 39006 & 15002330 & 2009.24 & 0.01181 & 3.146 & 16.7417 & 3727 \\
$F_{6}$ & $6.031 \times 10^{-5}$ & 98.5 & 0.0013826 & & & & \\
$F_{7}$ & 11747 & 55.033 & 4521 & 0.01998 & 0.00604 & 3347.4 & 0.00475 \\
$F_{8}$ & 0.01543 & 13.29 & 0.01807 & 0.0011 & $8.81 \times 10^{-5}$ & 0.0405 & 26.74 \\
$F_{p}$ & 0.4922 & 0.86 & & & & & \\
$F_{\text {veg }}$ & 0.17 & 0.41 & 9.25 & & & & \\
$D_{86}$ & 8.321 & 0.14249 & 0.96655 & 0.01 & 20.0 & 0.0429 & \\
\hline
\end{tabular}

\section{Appendix B: A simplified approximation}

As the analysis in this work has shown, the conventional horizontal weighting function can underrate soil moisture near the sensor by factors of up to 25 . Furthermore, the variability of the radial weighting function $W_{r}(h, \theta)$ with environmental conditions can have a significant influence on the soil moisture average, where accuracy matters. In cases where simplicity and computational efficiency are criteria, an approximated weighting function $W_{r}^{*}$ can be proposed, which is an averaged formulation over dry and wet conditions:

$\left\langle W_{r}(h, \theta)\right\rangle_{h, \theta} \approx W_{r}^{*}=$
$\begin{cases}\left(30 e^{-r^{*} / 1.6}+e^{-r^{*} / 100}\right)\left(1-e^{-3.7 r^{*}}\right), & 0 \mathrm{~m}<r \leq 1 \mathrm{~m} \\ 30 e^{-r^{*} / 1.6}+e^{-r^{*} / 100}, & r>1 \mathrm{~m} .\end{cases}$

Figure 2 shows the decent compromise performed by this approximation for both short-range and long-range neutrons. Tests with all datasets of this study have indicated that the corresponding soil moisture average deviates from the exactly weighted average by no more than $\Delta \theta_{\mathrm{v}}<2 \%$ (not shown). However, the deviation highly depends on $h$ and $\theta$ and thus can be an important source of error in temporal analysis where large ranges of humidity are expected. Also note that the integral of the approximated function does not scale with neutron intensity anymore, which has however no impact on normalized weights.

Further studies will demonstrate whether Eq. (B1) is accurate enough to improve the CRNS performance under various wetness conditions and in different sites. If so, the reduction of computational effort will be valuable for regular analysis and for end users in the applied sector.

\section{Appendix C: Toolbox for spatial weighting of point data}

Proper horizontal and vertical weighting of point measurements is a prerequisite for validation and calibration of the CRNS method. Before the publication of Köhli et al. (2015) almost all users of CRNS probes avoided horizontal weighting. However, the revised neutron physics model reveals a highly nonlinear shape of the detector's radial sensitivity. The corresponding publication has been distributed with the Supplement that provided the weighting functions $W_{r}$ as readyto-apply Excel, R, and MATLAB scripts. As the present study advanced the analytical fits of the spatial sensitivity functions (Appendix A), the corresponding updated script files can be found in the Supplement.

Moreover, an easy-to-use toolbox has been prepared in the form of an Excel sheet to guide users through the weighting process. This sheet is able to take a snapshot of point data around the sensor and calculates the corresponding CRNS footprint $R_{86}$, the average penetration depth $D_{86}$, and the weighted average soil water content according to guidelines in this paper. 


\section{The Supplement related to this article is available online at https://doi.org/10.5194/hess-21-5009-2017- supplement.}

Competing interests. The authors declare that they have no conflict of interest.

Acknowledgements. Martin Schrön acknowledges kind support by the Helmholtz Impulse and Networking Fund through the Helmholtz Interdisciplinary School for Environmental Research (HIGRADE). Joost Iwema is funded by the Queen's School of Engineering, University of Bristol, EPSRC, grant code EP/L504919/1. Rafael Rosolem, Joost Iwema, and Sheepdrove Organic Farm activities are funded by the Natural Environment Research Council (A MUlti-scale Soil moistureEvapotranspiration Dynamics study - AMUSED; grant number NE/M003086/1). Gabriele Baroni had financial support from the Deutsche Forschungsgemeinschaft (DFG) under CI 26/13-1 in the framework of research unit FOR 2131 "Data Assimilation for Improved Characterization of Fluxes across Compartmental Interfaces". Corinna Rebmann and Matthias Cuntz acknowledge the support of this study by the Integrated Carbon Observation System (ICOS) infrastructure through the Federal Ministry of Research and Education (BMBF). We acknowledge the NMDB database (http://www.nmdb.eu), founded under the European Union's FP7 programme (contract no. 213007) to provide data for incoming radiation, especially from monitors Jungfraujoch (Physikalisches Institut, University of Bern) and Kiel (Institute for Experimental and Applied Physics, University of Kiel). The research was funded and supported by the Terrestrial Environmental Observatories (TERENO), which is a joint collaboration program involving several Helmholtz Research Centers in Germany.

The article processing charges for this open-access

publication were covered by a Research

Centre of the Helmholtz Association.

Edited by: Bob Su

Reviewed by: Yijian Zeng and three anonymous referees

\section{References}

Almeida, A. C., Dutta, R., Franz, T. E., Terhorst, A., Smethurst, P. J., Baillie, C., and Worledge, D.: Combining Cosmic-Ray Neutron and Capacitance Sensors and Fuzzy Inference to Spatially Quantify Soil Moisture Distribution, IEEE Sensors J., 14, 34653472, https://doi.org/10.1109/JSEN.2014.2345376, 2014.

Baatz, R., Bogena, H., Franssen, H.-J. H., Huisman, J., Qu, W., Montzka, C., and Vereecken, H.: Calibration of a catchment scale cosmic-ray probe network: A comparison of three parameterization methods, J. Hydrol., 516, 231-244, https://doi.org/10.1016/j.jhydrol.2014.02.026, 2014.

Baroni, G. and Oswald, S.: A scaling approach for the assessment of biomass changes and rainfall interception us- ing cosmic-ray neutron sensing, J. Hydrol., 525, 264-276, https://doi.org/10.1016/j.jhydrol.2015.03.053, 2015.

Bogena, H. R., Herbst, M., Huisman, J., Rosenbaum, U., Weuthen, A., and Vereecken, H.: Potential of wireless sensor networks for measuring soil water content variability, Vadose Zone J., 9, 1002-1013, 2010.

Bogena, H. R., Huisman, J. A., Baatz, R., Hendricks Franssen, H.-J., and Vereecken, H.: Accuracy of the cosmic-ray soil water content probe in humid forest ecosystems: The worst case scenario, Water Resour. Res., 49, 5778-5791, https://doi.org/10.1002/wrcr.20463, 2013.

Bogena, H. R., Huisman, J. A., Güntner, A., Hübner, C., Kusche, J., Jonard, F., Vey, S., and Vereecken, H.: Emerging methods for noninvasive sensing of soil moisture dynamics from field to catchment scale: a review, Wiley Interdisciplin. Rev.: Water, 2, 635-647, 2015.

Ceppi, A., Ravazzani, G., Corbari, C., Salerno, R., Meucci, S., and Mancini, M.: Real-time drought forecasting system for irrigation management, Hydrol. Earth Syst. Sci. 18, 3353-3366, https://doi.org/10.5194/hess-18-3353-2014, 2014.

Coopersmith, E. J., Cosh, M. H., and Daughtry, C. S.: Field-scale moisture estimates using COSMOS sensors: A validation study with temporary networks and Leaf-Area-Indices, J. Hydrol., 519, 637-643, https://doi.org/10.1016/j.jhydrol.2014.07.060, 2014.

Desilets, D. and Zreda, M.: Footprint diameter for a cosmic-ray soil moisture probe: Theory and Monte Carlo simulations, Water Resour. Res., 49, 3566-3575, https://doi.org/10.1002/wrcr.20187, 2013.

Desilets, D., Zreda, M., and Ferré, T.: Nature's neutron probe: Land surface hydrology at an elusive scale with cosmic rays, Water Resour. Res., 46, W11505, https://doi.org/10.1029/2009WR008726, 2010.

Dong, J., Ochsner, T. E., Zreda, M., Cosh, M. H., and Zou, C. B.: Calibration and Validation of the COSMOS Rover for Surface Soil Moisture Measurement, Vadose Zone J., 13, 4, https://doi.org/10.2136/vzj2013.08.0148, 2014.

Etmann, M.: Dendrologische Aufnahmen im Wassereinzugsgebiet oberer Wüstebach anhand verschiedener Mess-und Schätzverfahren, Westfälische Wilhelms-Universität, Münster, Germany, 2009.

Evans, J. G., Ward, H. C., Blake, J. R., Hewitt, E. J., Morrison, R., Fry, M., Ball, L. A., Doughty, L. C., Libre, J. W., Hitt, O. E., Rylett, D., Ellis, R. J., Warwick, A. C., Brooks, M., Parkes, M. A., Wright, G. M. H., Singer, A. C., Boorman, D. B., and Jenkins, A.: Soil water content in southern England derived from a cosmic-ray soil moisture observing system - COSMOS-UK, Hydrol. Process., 30, 4987-4999, https://doi.org/10.1002/hyp.10929, 2016.

Franz, T. E., Zreda, M., Rosolem, R., and Ferré, T.: Field Validation of a Cosmic-Ray Neutron Sensor Using a Distributed Sensor Network, Vadose Zone J., 11, 4, https://doi.org/10.2136/vzj2012.0046, 2012a.

Franz, T. E., Zreda, M., Ferré, T. P. A., Rosolem, R., Zweck, C., Stillman, S., Zeng, X., and Shuttleworth, W. J.: Measurement depth of the cosmic ray soil moisture probe affected by hydrogen from various sources, Water Resour. Res., 48, W08515, https://doi.org/10.1029/2012WR011871, 2012b.

Franz, T. E., Zreda, M., Rosolem, R., Hornbuckle, B. K., Irvin, S. L., Adams, H., Kolb, T. E., Zweck, C., and Shuttleworth, 
W. J.: Ecosystem-scale measurements of biomass water using cosmic ray neutrons, Geophys. Res. Lett., 40, 3929-3933, https://doi.org/10.1002/grl.50791, 2013a.

Franz, T. E., Zreda, M., Ferré, T. P. A., and Rosolem, R.: An assessment of the effect of horizontal soil moisture heterogeneity on the area-average measurement of cosmic-ray neutrons, Water Resour. Res., 49, 6450-6458, https://doi.org/10.1002/wrcr.20530, 2013b.

Fu, C.-C., Wang, P.-K., Lee, L.-C., Lin, C.-H., Chang, W.-Y., Giuliani, G., and Ouzounov, D.: Temporal variation of gamma rays as a possible precursor of earthquake in the Longitudinal Valley of eastern Taiwan, J. Asian Earth Sci., 114, 362-372, https://doi.org/10.1016/j.jseaes.2015.04.035, 2015.

Glaser, B., Klaus, J., Frei, S., Frentress, J., Pfister, L., and Hopp, L.: On the value of surface saturated area dynamics mapped with thermal infrared imagery for modeling the hillsloperiparian-stream continuum, Water Resour. Res., 52, 8317-8342, https://doi.org/10.1002/2015WR018414, 2016.

Gottselig, N., Wiekenkamp, I., Weihermüller, L., Brüggemann, N., Berns, A. E., Bogena, H. R., Borchard, N., Klumpp, E., Lücke, A., Missong, A., Pütz, T., Vereecken, H., Huisman, J. A., and Bol, R.: A Three-Dimensional View on Soil Biogeochemistry: A Dataset for a Forested Headwater Catchment, J. Environ. Qual., 46, 210-218, 2017.

Gupta, H. V., Kling, H., Yilmaz, K. K., and Martinez, G. F.: Decomposition of the mean squared error and NSE performance criteria: Implications for improving hydrological modelling, J. Hydrol., 377, 80-91, 2009.

Hawdon, A., McJannet, D., and Wallace, J.: Calibration and correction procedures for cosmic-ray neutron soil moisture probes located across Australia, Water Resour. Res., 50, 5029-5043, https://doi.org/10.1002/2013WR015138, 2014.

Heidbüchel, I., Güntner, A., and Blume, T.: Use of cosmic-ray neutron sensors for soil moisture monitoring in forests, Hydrol. Earth Syst. Sci., 20, 1269-1288, https://doi.org/10.5194/hess-201269-2016, 2016.

Iwema, J., Rosolem, R., Baatz, R., Wagener, T., and Bogena, H. R.: Investigating temporal field sampling strategies for sitespecific calibration of three soil moisture-neutron intensity parameterisation methods, Hydrol. Earth Syst. Sci., 19, 3203-3216, https://doi.org/10.5194/hess-19-3203-2015, 2015.

Jarraud, M.: Guide to meteorological instruments and methods of observation, WMO-No. 8, World Meteorological Organisation, Geneva, Switzerland, 2008.

Köhli, M., Schrön, M., Zreda, M., Schmidt, U., Dietrich, P., and Zacharias, S.: Footprint characteristics revised for field-scale soil moisture monitoring with cosmic-ray neutrons, Water Resour. Res., 51, 5772-5790, https://doi.org/10.1002/2015WR017169, 2015.

Lv, L., Franz, T. E., Robinson, D. A., and Jones, S. B.: Measured and Modeled Soil Moisture Compared with Cosmic-Ray Neutron Probe Estimates in a Mixed Forest, Vadose Zone J., 13, https://doi.org/10.2136/vzj2014.06.0077, 2014.

Martini, E., Wollschläger, U., Kögler, S., Behrens, T., Dietrich, P., Reinstorf, F., Schmidt, K., Weiler, M., Werban, U., and Zacharias, S.: Spatial and temporal dynamics of hillslope-scale soil moisture patterns: Characteristic states and transition mechanisms, Vadose Zone J., 14, https://doi.org/10.2136/vzj2014.10.0150, 2015.
Nash, J. E. and Sutcliffe, J. V.: River flow forecasting through conceptual models part I - A discussion of principles, J. Hydrol., 10, 282-290, 1970.

Norbiato, D., Borga, M., Degli Esposti, S., Gaume, E., and Anquetin, S.: Flash flood warning based on rainfall thresholds and soil moisture conditions: An assessment for gauged and ungauged basins, J. Hydrol., 362, 274-290, 2008.

Rebmann, C., Göckede, M., Foken, T., Aubinet, M., Aurela, M., Berbigier, P., Bernhofer, C., Buchmann, N., Carrara, A., Cescatti, A., Ceulemans, R., Clement, R., Elbers, J. A., Granier, A., Grünwald, T., Guyon, D., Havránková, K., Heinesch, B., Knohl, A., Laurila, T., Longdoz, B., Marcolla, B., Markkanen, T., Miglietta, F., Moncrieff, J., Montagnani, L., Moors, E., Nardino, M., Ourcival, J.-M., Rambal, S., Rannik, Ü., Rotenberg, E., Sedlak, P., Unterhuber, G., Vesala, T., and Yakir, D.: Quality analysis applied on eddy covariance measurements at complex forest sites using footprint modelling, Theor. Appl. Climatol., 80, 121-141, 2005.

Rivera Villarreyes, C. A., Baroni, G., and Oswald, S. E.: Integral quantification of seasonal soil moisture changes in farmland by cosmic-ray neutrons, Hydrol. Earth Syst. Sci., 15, 3843-3859, https://doi.org/10.5194/hess-15-3843-2011, 2011.

Robinson, D., Campbell, C., Hopmans, J., Hornbuckle, B., Jones, S. B., Knight, R., Ogden, F., Selker, J., and Wendroth, O.: Soil moisture measurement for ecological and hydrological watershedscale observatories: A review, Vadose Zone J., 7, 358-389, 2008.

Samaniego, L., Kumar, R., and Zink, M.: Implications of Parameter Uncertainty on Soil Moisture Drought Analysis in Germany, J. Hydrometeorol., 14, 47-68, https://doi.org/10.1175/jhm-d-12075.1, 2013.

Schattan, P., Baroni, G., Oswald, S. E., Schöber, J., Fey, C., Kormann, C., Huttenlau, M., and Achleitner, S.: Continuous monitoring of snowpack dynamics in alpine terrain by aboveground neutron sensing, Water Resour. Res., 53, 3615-3634, https://doi.org/10.1002/2016WR020234, 2017.

Scheiffele, L. M.: Assessment of soil moisture dynamics on an irrigated maize field using cosmic ray neutron sensing, MS thesis, Institute of Earth and Environmental Science, University of Potsdam, Potsdam, Germany, 2015.

Schrön, M., Zacharias, S., Köhli, M., Weimar, J., and Dietrich, P.: Monitoring Environmental Water with Ground Albedo Neutrons and Correction for Incoming Cosmic Rays with Neutron Monitor Data, in: 34th International Cosmic-Ray Conference (ICRC 2015), Proceedings of Science, http://pos.sissa.it/archive/ conferences/236/231/ICRC2015_231.pdf (last access: 2 October 2017), 2015.

Sheffield, J.: A simulated soil moisture based drought analysis for the United States, J. Geophys. Res., 109, D24108, https://doi.org/10.1029/2004jd005182, 2004.

Smith, M., Kivumbi, D., and Heng, L. K.: Use of the FAO CROPWAT model in deficit irrigation studies, in: Deficit irrigation practices, Food and Agriculture Organization of the United Nations (FAO), 2002.

Vereecken, H., Huisman, J. A., Bogena, H., Vanderborght, J., Vrugt, J. A., and Hopmans, J. W.: On the value of soil moisture measurements in vadose zone hydrology: A review, Water Resour. Res., 44, W00D06, https://doi.org/10.1029/2008WR006829, 2008. 
Wiekenkamp, I., Huisman, J., Bogena, H., Lin, H., and Vereecken, H.: Spatial and temporal occurrence of preferential flow in a forested headwater catchment, J. Hydrol., 534, 139-149, 2016.

Wollschläger, U., Attinger, S., Borchardt, D., Brauns, M., Cuntz, M., Dietrich, P., Fleckenstein, J. H., Friese, K., Friesen, J., Harpke, A., Hildebrandt, A., Jäckel, G., Kamjunke, N., Knöller, K., Kögler, S., Kolditz, O., Krieg, R., Kumar, R., Lausch, A., Liess, M., Marx, A., Merz, R., Mueller, C., Musolff, A., Norf, H., Oswald, S. E., Rebmann, C., Reinstorf, F., Rode, M., Rink, K., Rinke, K., Samaniego, L., Vieweg, M., Vogel, H.J., Weitere, M., Werban, U., Zink, M., and Zacharias, S.: The Bode hydrological observatory: a platform for integrated, interdisciplinary hydro-ecological research within the TERENO Harz/Central German Lowland Observatory, Environ. Earth Sci., 76, 29, https://doi.org/10.1007/s12665-016-6327-5, 2016.

Zacharias, S., Bogena, H., Samaniego, L., Mauder, M., Fuß, R., Pütz, T., Frenzel, M., Schwank, M., Baessler, C., ButterbachBahl, K., Bens, O., Borg, E., Brauer, A., Dietrich, P., Hajnsek, I., Helle, G., Kiese, R., Kunstmann, H., Klotz, S., Munch, J. C., Papen, H., Priesack, E., Schmid, H. P., Steinbrecher, R., Rosenbaum, U., Teutsch, G., and Vereecken, H.: A Network of Terrestrial Environmental Observatories in Germany, Vadose Zone J., 10, 955-973, https://doi.org/10.2136/vzj2010.0139, 2011.
Zink, M., Samaniego, L., Kumar, R., Thober, S., Mai, J., Schäfer, D., and Marx, A.: The German drought monitor, Environ. Res. Lett., 11, 074002, https://doi.org/10.1088/17489326/11/7/074002, 2016.

Zreda, M., Desilets, D., Ferré, T. P. A., and Scott, R. L.: Measuring soil moisture content non-invasively at intermediate spatial scale using cosmic-ray neutrons, Geophys. Res. Lett., 35, L21402, https://doi.org/10.1029/2008GL035655, 2008.

Zreda, M., Shuttleworth, W. J., Zeng, X., Zweck, C., Desilets, D., Franz, T., and Rosolem, R.: COSMOS: The COsmic-ray Soil Moisture Observing System, Hydrol. Earth Syst. Sci., 16, 4079_ 4099, https://doi.org/10.5194/hess-16-4079-2012, 2012. 